\title{
Adolf Bauser (1880-1948), der Sparerbund und die Volksrechtpartei
}

\author{
Von Hans Peter Müller
}

Treffend beschrieb Gustav Stresemann in seiner Rede bei der Verleihung des Friedensnobelpreises 1927 in Oslo Deutschlands „schwersten Verlust“ nach dem Endes des ersten Weltkrieges mit der Tatsache, „dass jene geistige und gewerbliche Mittelschicht, die traditionsgemäß Trägerin des Staatsgedankens war, ihre völlige Hingabe an den Staat im Kriege mit der völligen Aufgabe ihres Vermögens bezahlte und proletarisiert wurde.“ Er gestand ferner zu, dass „der Streit der Geister und vielleicht auch die Praxis der Gesetzgebung bis heute nicht zum Abschluß gekommen" sei.

Hintergrund dieser Ausführungen war die „systematische Enteignung des deutschen Mittelstandes“ durch eine bürgerliche Regierung - „eine der größten Räube-

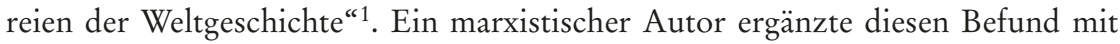
der Feststellung, dass die Inflationspolitik der Reichsregierung es einer „kleinen Gruppe von Konzern- und Bankherren, Großagrariern, Schiebern und Spekulanten“- Hugo Stinnes mag hier als Paradebeispiel dienen - , ermöglichte, sich „hemmungslos“ zu bereichern, während die Mittelschichten, Sparer, Anleihenbesitzer, Hypothekengläubiger und viele andere ohne nennenswerten Sachbesitz mehr oder weniger ruiniert wurden ${ }^{2}$. Diese Befunde wurden auch von bürgerlichen Historikern mehr oder weniger geteilt ${ }^{3}$.

Während der amerikanische Historiker Michael L. Hughes zu Recht betont, die Gläubiger hätten in der Inflationspolitik der Regierung einen Verrat gegebener

1 Stresemann-Zitat und Autoren-Bewertung nach Arthur Rosenberg, Geschichte der Weimarer Republik, Frankfurt/M. 1970, S. 129.

2 Werner Fritsch, Art. Sparerbund für das Deutsche Reich (Spb) 1923-1939, in: Lexikon zur Parteiengeschichte, Bd. 4, Leipzig 1986, S.137f.

${ }^{3}$ Vgl. etwa Helmut Heiber, Die Republik von Weimar, München 1966, insbesondere S. 98; Hans-Ulrich WeHler, Deutsche Gesellschaftsgeschichte 1914-1949, München 2003, S. 247 ff., der das anhaltende „Inflationstrauma“ der Geschädigten betont (S. 249); Heinrich August Winkler, Weimar 1918-1933, München 1998, S. 244 f. In diesen wie auch in weiteren Darstellungen zur Weimarer Republik wird, soweit ich sehe, der Sturmlauf des Sparerbundes und der Volksrechtpartei (VRP) gegen die Aufwertungsregelung praktisch ignoriert. 
Versprechen erblickt ${ }^{4}$, schrieb der Stuttgarter SPD-Politiker Wilhelm Keil, der als Reichstagsabgeordneter und Experte seiner Partei das parlamentarische Tauziehen um das „Drama“ Aufwertung miterlebte, „das Aufwertungskapitel“ sei „eines der trübsten in der Geschichte der Weimarer Republik" gewesen5.

\section{Die Formierung der Inflationsgeschädigten - der Kampf „David gegen Goliath“}

In Württemberg und im Reich trat zu Beginn der 1920er Jahre der Pädagoge Adolf Bauser ${ }^{6}$ an die Spitze der Inflationsgeschädigten. Im „Kampf um eine gerechte Aufwertung“, d.h. der „Wiedergutmachung des Unrechts der Inflationspolitik" sah er fortan seine eigentliche Lebensaufgabe. Er wollte nicht hinnehmen, dass die „ungeheuerliche Vermögensverschiebung“ durch die gewollte Inflation „auf der einen Seite eine Verarmung und Verelendung vor allem der wohlhabenden Schichten des Mittelstandes und der kleinen Sparer, auf der anderen Seite eine Bereicherung insbesondere derer, welche die Zeit bedenkenlos zu nutzen verstanden" ${ }^{\text {"7 }}$, durch die Politik der Reichsregierung sozusagen festgeschrieben wurde.

Als Keimzelle der Aktivitäten Bausers entstand 1922 in Stuttgart der von ihm geleitete „Bund gegen Wucher und Teuerung“, der im März 1923 Maßnahmen wie die wirksame Fortsetzung des Preisabbaus für einheimische Lebensmittel und Rohstoffe, den Verzicht auf Erhöhung der Verkehrstarife, staatliche und kommunale Gebühren einschließlich der Umsatz- und Kohlensteuer forderte. Zugleich sollten Lohn- und Gehaltserhöhungen unterbleiben, sofern die Preise auf deren Niveau herabgedrückt würden ${ }^{8}$. Schon wenige Wochen später wurde auf einer Versammlung des Bundes beschlossen, dem Anfang 1923 in Berlin gegründeten „Hypothekengläubiger-Schutzverband für das Deutsche Reich“ - dann „Hypothekengläubiger und Sparerschutzverband“, kurz „Sparerbund“ - als württembergischer Landesverband beizutreten. Zentrales Ziel sollte sein, mit aller Energie

\footnotetext{
${ }^{4}$ Michael L. Hughes, Paying for the German Inflation, Chapel Hill/London 1988, S. 10.

5 Wilhelm KeIL, Erlebnisse eines Sozialdemokraten, Bd. 1, Stuttgart 1947, S. 305.

${ }^{6}$ Der 1880 in Entringen bei Tübingen Geborene absolvierte am Lehrerseminar Nagold seine Ausbildung, um dann als Volksschul- und Reallehrer zu wirken. Nach einem Studium (1910-1913) der Pädagogik, Philosophie und Geschichte in Tübingen und Lausanne wurde er 1913 zum Professor am Nagolder Seminar ernannt, wo er von 1924-1931 als Direktor wirkte. Vorher hatte er seinen Kriegsdienst absolviert. Von 1931 bis 1939 war er Oberschulrat in Stuttgart. Vgl. zu seiner Vita: Biographisches Handbuch der württembergischen Landtagsabgeordneten 1815-1933, bearb. von Frank RaBERG, Stuttgart 2001, S. 37 f.; Hans Bauser, Adolf Bauser, in: Württembergische Biographien, Bd.1, hg. von Maria Magdalena RÜCKERT, Stuttgart 2006, S.9-11.

7 Adolf Bauser, Die Geschichte des Aufwertungskampfes, in: Für Wahrheit und Recht. Der Endkampf um eine gerechte Aufwertung. Reden und Aufsätze, Stuttgart [1927], S. 5 f.

8 Kocherbote Gaildorf (fortan KB) Nr. 65 vom 19.3.1923.
} 
in Verbindung mit der Reichsorganisation den unverzüglichen Erlaß eines Reichsgesetzes zu betreiben, das die Gläubiger davor bewahren sollte, sich für abgefunden zu erklären ${ }^{9}$.

Mit der Bezeichnung „Sparerbund“ wurde dokumentiert, dass dessen Wirkungsfeld nunmehr „den ganzen Kreis der durch die Inflationspolitik vernichteten Vermögen und Kapitalsanlagen “ umfasste ${ }^{10}$. Während schon 1923 im ganzen Reich Ortsgruppen entstanden, wuchs auch der von Bauser geführte Landesverband kontinuierlich und verfügte bald über Ortsvereine auch in kleineren Städten. Seit seinem Gründungsjahr erschien als Organ die von ihm herausgegebene „Selbsthilfe“, zunächst einmal, ab Anfang 1925 dann zweimal monatlich; in Stuttgart wurde ein Büro unterhalten.

Die neue Bewegung erhielt frühzeitig juristische Schützenhilfe. Anfang 1923 stellte der frühere badische Justizminister Düringer im Reichstag den Antrag, per Sperrgesetz „eine Rückzahlung der Hypotheken in entwertetem Gelde für eine bestimmte Zeit zu sperren“ und zwischenzeitlich eine befriedigende Lösung zu suchen. Seine Initiative wurde jedoch im Rechtsausschuss „begraben“11. Kurz nach Düringer initiierte der Präsident des Darmstädter Oberlandesgerichts, Dr. Best, ein Urteil, das den von der Reichsregierung vertretenen aufwertungsfeindlichen Grundsatz „Mark ist gleich Mark“ als nicht verfassungskonform verwarf und stattdessen das Prinzip von „Treu und Glauben“ etablierte. Auch ein Kölner Gericht urteilte ähnlich. Nachdem im Herbst 1923 die Rentenmark eingeführt wurde, schloss sich das Reichsgericht in Leipzig dieser Sicht an und sprach sich für eine Hypothekenaufwertung aus ${ }^{12}$.

Der Stuttgarter Verband begrüßte das Leipziger Urteil, habe es doch bei vielen Sparern neuen Lebensmut ausgelöst und die Hoffnung genährt, wenigstens Teile ihres Vermögens wieder zu erlangen. Bauser betonte sein Vertrauen in die deutschen Richter, äußerte jedoch neue Sorgen, wolle doch die Reichsregierung in der kommenden dritten Steuernotverordnung die Aufwertung verbieten. Vorsorglich habe sein Verband dringende Eingaben an den Reichstag, den Reichsrat, die beteiligten Reichsministerien, den württembergischen Landtag, das Staatsministerium sowie das Justiz- und Finanzministerium gerichtet, in denen nachdrückliche Verwabrung gegen das Vorhaben eingelegt wurde, die zu Lasten der Gläubiger erzielten Gewinne für das Reich zu beschlagnabmen ${ }^{13}$.

Schließlich wandte sich Anfang Januar 1924 auch der Richterverein beim Reichsgericht gegen die Pläne der Reichsregierung. Nachdem auch aus der katholischen Kirche Widerstand kam, sah sich die Regierung Marx schließlich veranlasst, ihren

9 KB Nr.77 vom 4. 4.1923.

10 Adolf Bauser, Die Geschichte (wie Anm. 7) S.6.

11 Ebd., S. 6. Vgl. auch Hughes (wie Anm.4) S.26f.

12 Vgl. dazu Adolf Bauser, Die Geschichte (wie Anm.7) S.6; Fritsch (wie Anm.2)

S. 138; Hughes (wie Anm. 4) S.26; KeIl (wie Anm. 5) S. 306.

13 KB Nr.298 vom 19.12.1923. 
Kurs eines totalen Aufwertungsverbots aufzugeben ${ }^{14}$. Die Steuernotverordnung vom 14. Februar 1924 sah jedoch - ein unbefriedigendes Ergebnis - nur eine 15\%ige Aufwertung von während der Hochinflation zurückgezahlten Hypotheken vor, die jedoch erst 1932 fällig werden sollte ${ }^{15}$.

Obwohl dies im Prinzip einen ersten Erfolg darstellte, reagierte der Sparerbund mit reichsweiten Protesten. Während einer Stuttgarter Kundgebung bezeichnete Dr. Best, der zur Zentralfigur des Sparerbundes geworden war und als dessen Ehrenvorsitzender auf Reichsebene fungierte, die Verordnung als einen vollendeten Recbtsbruch, der vor allem den Mittelstand und die Mündel treffe. Kritische Worte äußerte dort auch Düringer, der sich auf eine Vielzahl von Beschwerden vor allem von Armen und Alten berief. Die von Bauser geleitete Veranstaltung artikulierte die Erwartung, dass der neue Reichstag unverzüglich eine Verbesserung vornehme; die Parteien wurden aufgefordert, Stellung zu beziehen ${ }^{16}$.

Die für den 4. Mai 1924 terminierte Reichstagswahl schien den Sparerschützern bei den Parteien durchaus Einfluss zu bieten. Keil berichtet, dass, wenn auch mit Unterschieden, „sich alle Parteien für die Aufwertung“ aussprachen, die Deutschnationalen sogar $100 \%$ versprachen ${ }^{17}$. Man war sich jedoch bewusst, dass hinter diesen Versprechungen namentlich bei den bürgerlichen und rechtsbürgerlichen Parteien vor allem auf den Gewinn von Stimmen gezielt und Entscheidungen vielfach vom „großen Geld“ - den Inflationsgewinnern - diktiert wurden. Während sich die Mehrzahl der Landesverbände gegen eigene Listen aussprach, beschritten Baden, Hessen, Pommern und Württemberg diesen Weg. Im „Kampfbund der Entrechteten und betrogenen Sparer" kandidierten u.a. Bauser und Dr. Best in Württemberg und konnten mit etwas über 30.000 Stimmen einen Achtungserfolg, jedoch kein Mandat erringen ${ }^{18}$. Der bisher der DDP angehörende Bauser wurde nach dem Wahlgang von den Demokraten ausgeschlossen ${ }^{19}$. Im Mai konnte der württembergische Sparerbund feststellen, dass da und dort örtliche Banken, Kassen und Vereine begonnen hätten, die Aufwertungspflicht anzuerkennen ${ }^{20}$.

Der Reichssparerbund präsentierte im Juni 1924 dem Reichstag einen Aufwertungs-Antrag, der von Best formuliert und nach Anhörung von Experten überarbeitet wurde. Gläubiger-Ansprüche sollten danach gemäß dem Prinzip von ,Treu und Glauben' behandelt werden, d.h. das ursprüngliche Wertverhältnis als Maß-

${ }^{14}$ Dazu Hughes (wie Anm. 4) S.56ff.

15 Vgl. etwa KeIl (wie Anm. 5) S. 307.

16 KB Nr.69 vom 21.3.1924. Vgl. zu einer früheren Protestversammlung KB Nr. 48 vom 26.2.1924.

17 KeIl (wie Anm. 5) S. 307.

18 Vgl. dazu Adolf Bauser, Die Geschichte (wie Anm.7) S.7, auch KB Nr.96 vom 24.4.1924 und Nr.100 vom 29.4.1924.

19 KB Nr.113 vom 14.5.1924.

20 KB Nr.119 vom 21.5.1924. 
stab gelten ${ }^{21}$. Der württembergische Bund initiierte im August eine Anzahl z.T. gut besuchter Versammlungen, auf denen gegen die Haltung des Reichsfinanzministeriums und des inzwischen etablierten Aufwertungsausschusses des Reichstags Stellung bezogen wurde. Der Best-Entwurf müsse als Grundlage der Verbandlungen dienen, die dritte Steuernotverordnung sei inakzeptabel ${ }^{22}$. Zur Erreichung dieses Ziels appellierte der Bund auch an die württembergische Regierung ${ }^{23}$ und sprach voller Misstrauen gegen die Reichsregierung und die Nutznießer der Inflation von einer Empörung der Gläubiger, die ihren Kampf umso zäher fortsetzen würden ${ }^{24}$. In diesem Zusammenhang berichtete Keil, dass im Aufwertungsausschuss „die deutschnationalen Großindustriellen, Großlandwirte und Hausbesitzer“ es strikt ablehnten, über die dritte Steuernotverordnung hinauszugehen ${ }^{25}$.

In einem längeren Artikel erläuterte Bauser den Best'schen Gesetzentwurf über die Umwertung alter Geldschulden ${ }^{26}$. Der zusammen mit dem Deutschen Rentnerbund eingereichte Entwurf ${ }^{27}$ habe zum Ziel, den Rechtsbruch der 3. St.-N.-V. $z u$ beseitigen, die bedrobten Sparer zu retten und das Ansehen des Reiches als Rechts- und Kulturstaat wiederherzustellen. Er formuliere Mindestforderungen, die keineswegs eine Auf-, sondern vielmehr eine Umwertung in die neue Währung anstrebten, basiere auf dem vorjährigen Reichsgerichtsurteil und fordere keinen schematische[n] Prozentsatz, sondern vielmehr individuelle Regelungen. Die bisherige Politik der Regierung und der Reichsbank habe die Kaufkraft weiter Volkskreise vernichtet, ferner den Sparsinn getötet und die Kreditnot so zur Katastrophe gesteigert. Nur eine gerechte Aufwertung könne hier Abhilfe schaffen und liege so im Interesse aller.

Im Vorfeld der Reichstagswahl im Dezember 1924 wurde die Frage der politischen Interessenvertretung erneut - und kontrovers - diskutiert. In einer Vertreterversammlung des Reichsbundes votierte eine Minderheit für eigene Listen, die Mehrheit befürwortete jedoch, führende Repräsentanten auf den Wahlvorschlägen der scheinbar aufwertungsfreundlichen Parteien zu platzieren. Best erhielt so „als Lockvogel“ einen aussichtsreichen Platz bei der DNVP, die sich für seinen Entwurf aussprach ${ }^{28}$ und wurde gewählt. Ein weiterer Repräsentant, Seiffert, konnte ein Mandat bei den Völkischen gewinnen ${ }^{29}$.

\footnotetext{
21 KB Nr. 146 vom 24.6.1924.

22 KB Nr.186 vom 9.8.1924.

23 KB Nr.191 vom 15.8.1924.

${ }^{24} \mathrm{~KB}$ Nr. 197 vom 22.8.1924.

${ }^{25}$ KeIL (wie Anm. 5) S. 308.

${ }^{26}$ Er erschien auf der Titelseite des KB Nr.229 vom 29.9.1924 und war auch im Verbandsorgan „Selbsthilfe“ abgedruckt.

${ }_{27}$ Gegen ihn richtete sich sofort ein wahres Trommelfeuer der Wirtschaft und der Inflationsgewinner. Hughes (wie Anm. 4) S. 84.

${ }_{28}$ KeIl (wie Anm. 5) S. 309.

29 Adolf Bauser, Die Geschichte (wie Anm.7) S.7.
} 
1925 sollte zum „Höhepunkt“ (Wilhelm Keil) im Kampf um die Aufwertungsfrage werden. In diesem Bewusstsein bemühte sich der württembergische Sparerbund, seine Organisation zu stärken, obwohl er bereits landesweit über eine sebr große Zabl von Orts- und Kreisgruppen verfügte. Demzufolge sollte die „Selbsthilfe" nunmehr zweimal im Monat erscheinen. Es gelte ansonsten, die Neufassung und Erweiterung der Best'schen Entwürfe abzuwarten ${ }^{30}$.

Die am 15. Januar erfolgte Wahl des Aufwertungsgegners Luther zum Reichskanzler war für Bauser „ein Schlag ins Gesicht“ der Millionen von Betroffenen ${ }^{31}$. Energisch wurden die Behauptungen der wirtschaftlichen Spitzenverbände zurückgewiesen, die durchgreifende Neuregelung der Aufwertung bedeute den Ruin der Wirtschaft. Namhafte Wissenschaftler hätten dies längst widerlegt ${ }^{32}$. Man setzte nun große Hoffnungen auf die in die Reichsregierung eingetretene DNVP, hatte sich doch Staatspräsident Bazille zu einer gerechten Lösung bekannt ${ }^{33}$. Zudem erhoffte man Unterstützung durch den Reichspräsidenten Hindenburg, dessen Kandidatur man befürwortet hatte ${ }^{34}$.

Die seit Frühjahr 1925 vor allem im Aufwertungsausschuss des Reichstags laufenden dramatischen Auseinandersetzungen zeigten den Inflationsopfern überdeutlich, dass hier ein ungleicher Kampf tobte. Namentlich die Deutschnationalen führten auf Druck ihres Finanz- und Industrieflügels zunächst „einen Eiertanz auf“, der schließlich in einen „grandiosen Wahlbetrug“ mündete. Sie zogen Best, der auf der Erfüllung der gegebenen Versprechen beharrte, aus dem Ausschuss zurück, was ihn veranlasste, als Gast bei den Völkischen einzutreten. Gleichzeitig stellte ihm die SPD einen ihrer Ausschuss-Sitze zur Verfügung, wo er die Regierungsvorschläge, die „hinter den bescheidensten Erwartungen weit zurück“ blieben, heftig kritisierte ${ }^{35}$. Seinen Gegnern rief er $\mathrm{zu}$, dass er die Interessen der Betrogenen vertrete, Sie aber die Interessen der Diebe ${ }^{36}$.

Die schließlich im Juli 1925 verkündeten Aufwertungsgesetze, für deren Verbesserung neben Best auch Keil eintrat ${ }^{37}$, galten Bauser als „Farce“, obwohl er zugestand, dass sie dennoch „einen weiteren sichtbaren Erfolg des Kampfes“

30 Bericht von der Landesversammlung im KB Nr. 8 vom 12.1.1925.

31 Adolf BAuser, Die Geschichte (wie Anm.7) S.7.

32 Entschließung des württembergischen Sparerbundes, KB Nr. 49 vom 28.2.1925.

33 Staats-Anzeiger für Württemberg (fortan StAnz) Nr. 69 vom 24.3.1925. Der aufwertungsfreundliche Bazille schrieb Bauser 1927, er sei mit dessen Haltung in der Aufwertungsfrage völlig einverstanden. Vgl. Warren Ernest GADE, Württemberg and the Reich $1924-$ 1928, masch. Diss. Stanford 1971, S. 244.

${ }^{34}$ Vgl. KB Nr. 89 vom 18.4.1925 und Nr.93 vom 23.4.1925 (Anzeige), auch Adolf Bauser, Die Geschichte (wie Anm.7) S. 7 ff.

${ }^{35}$ KeIL (wie Anm. 5) S.310f., 314.

${ }^{36}$ Zitiert nach einer Rede des Reichstagsabgeordneten Seiffert in Ludwigsburg, laut Selbsthilfe Nr.21/22 vom 15.11.1925.

37 Er hatte zur Finanzierung höherer Sätze erfolglos eine Sondersteuer auf Inflationsgewinne vorgeschlagen. KeIL (wie Anm. 5) S.313. 
darstellten ${ }^{38}$. Der zwischen den Koalitionsparteien erzielte schuldnerfreundliche Kompromiss ${ }^{39}$ wurde etwa von dem Stuttgarter DVP-Reichstagsmitglied Bickes mit der scheinheiligen Aussage verteidigt, man habe Rechtsauffassung und Wirtschaftserwägung vereinbaren müssen ${ }^{40}$. Während die Hoffnungen der Gläubiger auf Unterstützung durch Hindenburg unerfüllt blieben, kommentierte ein Provinzblatt, es gebe mancherlei an den Gesetzen [zu] tadeln, was insbesondere für den Sektor der privaten Gelder gelte. Demzufolge wurden noch bittere Nachwehen prognostiziert ${ }^{41}$. Schließlich kommentierte das Blatt noch den Schlußpunkt unter [der] Tragödie der Geldentwertung und verwies auf die scharfe Kritik der Öffentlichkeit und der Sparerschutzverbände. Keil und Best wurden als die hartnäckigsten Rufer im Streite bezeichnet, jedoch Unverständnis darüber geäußert, dass sie nicht anerkannten, dass man in weitestem Maße sozialen Gesichtspunkten gefolgt sei und Alten und Bedürftigen eine Bevorzugung gewährt habe. Abschließend konstatierte der Kommentar, dass zwar weiterhin agitatorische[s] Blendwerk zu erwarten sei, frohlockte jedoch, die Beruhigung der Wirtschaft ist erreicht ${ }^{42}$. Damit war das Leitmotiv benannt, unter dem der von Anfang an ungleiche Kampf von der Reichsregierung und den Gewinnern der Inflation geführt wurde.

\section{Die Fortsetzung des Kampfes - der Versuch eines Volksbegehrens}

Schon wenige Wochen nach der Verkündung der Aufwertungsgesetze begannen die Sparerbünde auf Reichs- und auf Landesebene, sich für die Fortsetzung ihres Kampfes zu rüsten. Allerdings war deren Organisation durch die Abspaltung verschiedener Gruppierungen geschwächt, auch wenn man in einer Arbeitsgemeinschaft zusammenarbeitete. Der Sparerbund blieb jedoch die stärkste Vertretung der Inflationsgeschädigten ${ }^{43}$.

Der württembergische Sparerbund erklärte auf seiner Landesversammlung Mitte August 1925, die gesetzliche Regelung könne als endgültige, den berechtigten Wünschen und Forderungen der Sparer gerecht werdende Lösung der Auf-

38 Adolf Bauser, Die Geschichte (wie Anm.7) S. 8 (auch zu weiteren Hintergründen).

${ }^{39}$ Er sah eine schematische Hypotheken-Aufwertung von $25 \%$ für Anleihen bzw. Schuldverschreibungen sowie für Spareinlagen von 12,5\% vor. Die Regelungen waren jeweils mit komplexen Bedingungen verbunden, auf die hier nicht näher eingegangen wird.

${ }^{40}$ KB Nr.224 vom 25.9.1925. Dessen Parteifreund Egelhaaf kritisierte dagegen die Aufwertungsgesetze scharf. Er sah darin „den Untergang der wertvollsten Volksschicht, des Mittelstandes“ und berichtete von zahlreichen „erschütternde[n] Briefe[n]“. Von diesen „Betrogenen“ könne „Patriotismus kaum mehr erwartet werden“. Gottlob Egelhaaf, Lebens-Erinnerungen, bearb. von Adolf Rapp (Veröffentlichungen der Kommission für Geschichtliche Landeskunde in Baden-Württemberg, Reihe A, Bd.5), Stuttgart 1960, S.166f.

${ }^{41}$ Leitartikel im KB Nr.164 vom 17.7.1925.

42 KB Nr. 165 vom 18.7.1925.

43 Vgl. dazu Fritsch (wie Anm.2) S.139f. 
wertungsfrage nicht anerkannt werden. Für den weiteren Widerstand müsse als neue Strategie unverzüglich die Durchführung eines Volksbegehrens in die Wege geleitet werden ${ }^{44}$. In einer Fülle landesweiter Versammlungen wurde nun monatelang für diesen Weg geworben ${ }^{45}$.

Einer der Höhepunkte dieser Kampagne war der Auftritt Bests in Stuttgart, wo er vor vielen Tausenden scharf mit der Reichsregierung und ihren parlamentarischen Helfern abrechnete. Den Einwand, die Wirtschaftslage lasse die Aufwertung nicht zu, wies er zurück: Er sei juristisch unerbört und wirtschaftlich ungerechtfertigt. Unter Wirtschaft verstïnden die großkapitalistischen Schuldner nur sich selbst. Sei schon die Steuernotverordnung des Vorjahres der schamloseste Rechtsbruch der Geschichte gewesen, so sei das jetzige Gesetz noch weit schlimmer - die Kriegsniederlage dürfe nicht Ursache einer ungeheuren Bereicherung sein. Er sei keineswegs Feind des ehrlich erworbenen Großkapitals, jedoch ein solcher des durch Lug und Trug gewonnenen Reichtums. Seine Parteienschelte zielte vor allem auf die DNVP, die im Wahlkampf am lautesten die Aufwertung vertreten habe, um dann gegen Mitglieder Terror auszuüben. Der fortzusetzende Kampf sei ein solcher um das Recht und insofern sittliche Pflicht ${ }^{46}$.

Im Herbst 1925 liefen die Vorbereitungen zum Volksbegehren auf Hochtouren, Best hatte Vorschläge für die erforderlichen Gesetzentwürfe vorbereitet. Die Mitglieder des württembergischen Bundes wurden aufgefordert, zur Bestreitung der Kosten einen Sonderbeitrag von mindestens 3 Mark zu leisten ${ }^{47}$. Gleichzeitig wandte sich der Sparerbund mit einer Eingabe an die württembergische Regierung und den Landtag. Der Regierung wurde für ihre aufwertungsfreundliche Haltung gedankt, hatte sie doch schon im Juli im Reichsrat, wenn auch erfolglos, Einspruch gegen das Aufwertungsgesetz erhoben ${ }^{48}$. Nunmehr wurde darum gebeten, eine über die Reichsgesetzgebung hinausgehende landesgesetzliche Regelung zu schaffen, die vorteilhaft für das Land sei und reichsweit als Vorbild wirke ${ }^{49}$. Schließlich artikulierte der Reichstagsabgeordnete Seiffert, ein führender Vertreter des Reichsverbandes, einen weiteren gravierenden Vorbehalt gegen die neue Mietzinssteuer. Diese für den allgemeinen Finanzbedarf erhobene Sondersteuer gehe fast ausschließlich auf Kosten der Sparer und Hypothekengläubiger und müsse daher eben-

${ }^{44}$ KB Nr. 193 vom 20.8.1925. Zu dessen Vorbereitung hatte die Berliner Arbeitsgemeinschaft bereits Ende Juli aufgerufen. KB Nr.176 vom 31.7.1925.

${ }^{45}$ Vgl. etwa KB Nr. 205 vom 3. 9.1925 (Versammlung in Gaildorf), Selbsthilfe Nr. 21/22 vom 15.11.1925, S.14.

${ }^{46}$ KB Nr.214 vom 14.9.1925. Vgl. auch seinen Aufsatz: Dritte Steuernotverordnung, Aufwertungsgesetz und Gesetzentwurf des Sparerbundes, in: Für Wahrheit und Recht (wie Anm. 7) S. 12-22 mit ähnlicher Tendenz.

47 Selbsthilfe Nr.21/22 vom 15.11.1925, S. 15.

${ }^{48} \mathrm{~KB}$ Nr.178 vom 3.8.1925.

49 Selbsthilfe Nr.21/22 vom 15.11.1925, S. 1 f. 
falls bekämpft werden ${ }^{50}$. Während die Entwürfe von Best mehrfach umgearbeitet und auch den Landesverbänden vorgelegt wurden ${ }^{51}$, erfuhren sie im Dezember die Zustimmung der Zentrale. Die Einreichung verzögerte sich jedoch, da die Reichsarbeitsgemeinschaft einen eigenen Entwurf vorbereitete und Bausers Bemühungen um eine Einigung erfolglos blieben. Ende März 1926 beschloss daher der Reichssparerbund den Alleingang. Durch Ergänzungen im Interesse der Rentner, Mieter, Kriegsbeschädigten und Reichsbankgläubiger durfte man auf deren Unterstützung hoffen ${ }^{52}$. Insgesamt wurden erhebliche Verbesserungen angestrebt, indem sämtliche Ansprüche auf $50 \%$ des Goldmarkbetrages aufgewertet werden sollten ${ }^{53}$.

Schon bevor der Antrag des Sparerbundes am 27.4.1926 dem Innenministerium eingereicht wurde, war bekannt geworden, dass die Reichsregierung beabsichtige, die Initiative durch ein sogenanntes Sperrgesetz zu verhindern. Gegen dieses Vorhaben richteten sich dann reichsweite Proteste. So wandten sich die Sparerverbände Baden, Bayern, Hessen und Württemberg Anfang Juni in einer Stuttgarter Erklärung an den Reichspräsidenten, den Reichskanzler, die Reichstags-Fraktionen und die württembergische Regierung und forderten die unverzügliche Rücknahme bzw. Ablehnung des Sperrgesetzes ${ }^{54}$.

Einen besonderen Akzent erhielt die Initiative durch den Volksentscheid über die sogenannte Fürstenenteignung. Der Sparerbund empfahl seinen Anhängern zwar die Teilnahme, vermied jedoch eine inhaltliche Empfehlung. Man warf allerdings der Regierung und den die Fürsten unterstützenden Parteien vor, mit zweierlei Maß zu messen. Den Sparern verweigere man ihr Recht, das fürstliche Vermögen wolle man dagegen schützen. Einem Kritiker antwortete der erzürnte Bauser: Dieselbe Regierung und dieselben Parteien sind für Recht und Moral in der Frage der Fürstenabfindung und gegen Recht und Moral in unserer Sache ${ }^{55}$. Mit gleichem Tenor appellierte er sowohl an den Reichspräsidenten als auch an den Kanzler. Er verwies auf die Erbitterung der Sparer und erklärte, es dürfe nicht zweierlei Recht in Deutschland geben ${ }^{56}$.

Mitte Juni nahm der Reichstag den Antrag Best, das Sperrgesetz zu behandeln, zwar an, „taktische Manöver“ (Bauser) verhinderten jedoch dessen Beratung. Die Initiative, vor allem von SPD, DDP, KPD und den Völkischen unterstützt, wurde

50 Ebd., S. 13.

51 KB Nr. 285 vom 5.12.1925. - Zu den Aktivitäten der Württemberger gehörten auch die Präsentation eines eigenen Wahlvorschlags zu den Gemeinderatswahlen in Esslingen sowie Diskussionen um die Errichtung einer „Sparerbank“. Selbsthilfe Nr.21/22 vom 15.11.1925, S.15.

52 Dazu Adolf Bauser, Die Geschichte (wie Anm. 7) S. 8.

${ }^{53}$ Vorstellung des Gesetzentwurfes in Stuttgart, KB Nr.81 vom 9. 4.1926. Vgl. auch die Versammlung in Gaildorf, KB Nr.79 vom 7.4.1926.

54 KB Nr. 132 vom 10.6.1926.

55 Selbsthilfe Nr. 12 vom 30.6.1926, S. 2.

56 Die beiden Briefe ebd., S.6f. 
von der Regierung jedoch unterlaufen, indem sie das Sperrgesetz zurückzog. Best blieb auf seine Rückfrage, ob dies die Zulassung des Volksbegehrens bedeute, ohne Antwort, anschließend wurde der Reichstag bis November vertagt. Am 18. August 1926 beendete die Reichsregierung ihr klägliches Lavieren mit der endgültigen Ablehnung des Volksbegehrens ${ }^{57}$.

Während der württembergische Bund mit Entrüstung auf diese willkürlich[e] Entscheidung reagierte ${ }^{58}$, monierte Bauser das Regierungsverhalten als falsch und nicht verfassungskonform. Auch ein Pressekommentar empfand es als nicht nachvollziehbar und unkonsequent ${ }^{59}$. Bauser verwies im Rückblick darauf, dass man ursprünglich ein Sondergesetz plante, sich dann jedoch „in kühner Verdrehung“ der Realität auf die Reichsverfassung berief. Die Initiative wurde zum „Gesetz über den Staatshaushalt“ erklärt, der „über den Haufen geworfen“ würde. Nur der Reichspräsident könne darüber einen Volksentscheid veranlassen ${ }^{60}$.

Einziges Ergebnis des in Berlin inszenierten „Trauerspiels“, dem 1927 auch der Konkurrenzentwurf der Reichsarbeitsgemeinschaft zum Opfer fiel, waren „einige kleine Verbesserungen“ durch die Aufwertungsnovelle vom 9. Juli 1927, „das Unrecht der Aufwertungsgesetze [blieb] im wesentlichen“ bestehen ${ }^{61}$. Der Sparerbund verlagerte nun den Kampf auf eine andere Ebene, für die nun ein neues Instrument geschaffen wurde.

\section{Die Reichspartei für Volksrecht und Aufwertung/Volksrechtpartei (VRP)}

Aus der Sicht der sich düpiert und betrogen fühlenden und lauthals protestierenden Inflationsgeschädigten ${ }^{62}$ und ihrer Führer war es nachvollziehbar, dass man nicht daran dachte, den Widerstand aufzugeben. Ende August 1926 beschloss der Reichssparerbund im Verein mit verwandten Organisationen in Erfurt die Gründung der VRP, die allerdings wiederum nicht alle Verbände umfasste. Die Gründung dieser politischen Kampffront wurde in Stuttgart begrüßt; mit ihren Zielen war man voll einverstanden ${ }^{63}$.

${ }^{57}$ KB Nr.193 vom 20.8.1926. Vgl. zum Vorangehenden Adolf Bauser, Die Geschichte (wie Anm. 7) S. 9 f., Selbsthilfe Nr. 13 vom 17.7.1926, S.1f., 8 f. (Sparerbundsversammlung in Stuttgart, die die Zurückziehung des Sperrgesetzes begrüßte).

58 Versammlung in Stuttgart, KB Nr.196 vom 24.8.1926.

59 KB Nr. 199 vom 37.8.1926.

60 Adolf Bauser, Die Geschichte (wie Anm.7) S.9f. Vgl. auch Fritsch (wie Anm.2) S. $141 \mathrm{f}$.

61 Adolf Bauser, Die Geschichte (wie Anm. 7) S. $10 f$.

${ }^{62} \mathrm{Vgl}$. dazu etwa die Stuttgarter Sparerbund-Landesversammlung, KB Nr.209 vom 8.9.1926.

${ }^{63}$ Ebd. - Harsch wurde auch die Reichsregierung gerügt: Längst hätte sie die Aufgabe gehabt, die Kriegslasten durch Heranziehung der Kriegs- und Inflationsgewinnler zu regeln, 
Die neue Partei, für die der Reichsverband, dem inzwischen 29 Landesverbände angehörten ${ }^{64}$ sozusagen als „Dach“ fungierte, wählte Bauser an die Spitze; Stuttgart wurde auch zum Sitz des geschäftsführenden Vorstands bestimmt ${ }^{65}$. Er formulierte dann in einer längeren Abhandlung die „Notwendigkeit, Aufgaben und Ziele der Volksrechtpartei“"66. Dort betonte er eingangs, die bisherigen Erfahrungen hätten bewiesen, dass der Kampf mit und innerhalb der Parteien „aussichtslos“ geblieben sei. Deren Strukturen und ihre Beeinflussung „von starken wirtschaftlichen Interessen“ der Aufwertungsgegner hätten die „Schaffung einer eigenen Partei“ unabdingbar gemacht ${ }^{67}$. Euphorisch hoffte er, „Millionen von Wählern“ gewinnen zu können, schließlich seien die vielen Nichtwähler „nicht ,wahlmüde‘, sondern ,parteimüde“ “, ein „überparteiliche[r] Kampfbund“ also attraktiv ${ }^{68}$. Die erwartete Klientel waren natürlich „die Massen der Aufwertungsgeschädigten“, aber auch Rentner, Reichsbankgläubiger, Mieter und Kriegsbeschädigte, Kriegshinterbliebene, Vertriebene aus den verlorenen Gebieten, Beamte und Lehrer sowie um ihre Altersversorgung bangende Mittelständler ${ }^{69}$.

Den Vorwurf, „Splitterpartei“ zu werden, ließ er nicht gelten. Vielmehr prognostizierte er das Erscheinen neuer Parteien, die nicht weltanschaulich orientiert seien, sondern „auf wirtschafts- und sozialpolitischer Grundlage“ operierten. Für den Mittelstand, der nicht „zwischen Großkapital und dem Proletariat aufgerieben“ werden wolle, gelte es, sich neu zu gruppieren ${ }^{70}$. Keineswegs sei die VRP nur auf die Aufwertungsfrage fixiert. Nach „der Schmach des größten Währungsbetruges aller Zeiten“ bleibe sie aber dem „Kampf um die Grundlagen des Rechts- und Kulturstaats“ verpflichtet, „die Lüge der inneren Entschuldung“ müsse revidiert werden. Daher gelte es, die „Parteiregierung“ sowie „die Willkürherrschaft mächtiger wirtschaftlicher Interessengruppen zu bekämpfen“. Eine der Hauptaufgaben sei die „gerechte Verteilung der Lasten der Kriegs- und Nachkriegszeit auf alle Volksgenossen nach ihrer Leistungsfähigkeit“ zu erreichen. Dazu gehöre auch

statt einseitig deren Interessen zu vertreten. KB Nr.213 vom 13.9.1926. Eine spätere Stuttgarter Protesterklärung drohte sogar mit einer Ministeranklage wegen Verletzung der Reichsverfassung. KB Nr.255 vom 1.11.1926.

${ }^{64} \mathrm{~KB}$ Nr. 213 vom 13.9.1926.

${ }^{65} \mathrm{Vgl}$. Werner Fritsch, Art. Reichspartei für Volksrecht und Aufwertung (Volksrecht-Partei), in: Lexikon zur Parteiengeschichte 1789-1945, Bd.3, Leipzig 1985, hier S. 740 .

${ }^{66}$ Adolf Bauser, Notwendigkeit, Aufgaben und Ziele der Volksrechtpartei, in: Für Wahrheit und Recht (wie Anm.7) S.90-95. Daraus das Folgende.

${ }^{67}$ Ebd., S.90f. Bauser sprach dabei von den bürgerlichen Parteien und lobte allein die Völkischen. Die aufwertungsfreundliche SPD, ganz zu schweigen von der KPD, schieden für den ganz und gar bürgerlichen Bauser als Allianzpartner aus.

68 Ebd., S. 91.

69 Ebd., S. 92, 95.

70 Ebd., S. 92 f. 
der Widerstand gegen die „unsoziale Mietzinssteuer“. Zudem erstrebe man eine "gesunde Sparer- und Verbraucherpolitik ${ }^{71}$.

Während Bauser die VRP auf der Seite des Mittelstandes und der wirtschaftlich Schwachen verortete, artikulierte er dezidiert antikapitalistische Aussagen: „Die bisherige wirtschaftliche Entwicklung [habe] in bedrohlicher Weise“ dazu geführt, „das Kapital in wenigen Händen zu konzentrieren“ und „Ausbeutung“ und „Wucher“ gebracht. Der „skrupellosen Gewinnsucht“ setzte er „sittliche Güter“ - Bildung und „Schutz der Ehe und Familie“ - entgegen ${ }^{72}$.

Zur Außenpolitik forderte er etwa die Zurücknahme der „Kriegsschuldlüge“ und die Revision des Dawesplanes, die Rückgabe der Kolonien und eine allgemeine Abrüstung ${ }^{73}$.

Während diese Ziele auch bei den übrigen Parteien vielfach zu finden waren, stellten Bausers kämpferische Aussagen gegen das Großkapital und das „Kapitalistenrecht“ letztlich nur Rhetorik dar - die VRP war wie auch der Sparerbund keineswegs klassenkämpferisch orientiert. So blieb eigentlich fast nur ihr zentrales Anliegen einer gerechten Aufwertung übrig, durch die Deutschlands moralischer „Wiederaufbau“ zu einer wahren „Volksgemeinschaft“ erfolgen sollte ${ }^{74}$. Die Zukunft musste zeigen, ob die so zahlreich erwartete Klientel in der VRP eine wirkliche Alternative sah.

Immerhin konnte die Partei bei den sächsischen Landtagswahlen im Oktober 1926 etwa 98.000 Stimmen und damit vier Mandate erringen. Bauser frohlockte, man habe dort die Regierungsbildung beeinflusst und mit Dr. von Fumetti, dem stellvertretenden Reichsvorsitzenden, das Justizministerium besetzen können ${ }^{75}$. Die anschließenden Ergebnisse auf Landesebene fielen dann magerer aus: Im Januar 1927 wurde in Thüringen ein Mandat, im November 1927 in Hessen drei Sitze - einer davon ging an Best - erreicht.

In Württemberg waren wie anderswo Sparerbund und VRP praktisch identisch. Zur Führungsspitze gehörten Rechtsanwälte - Seeger und Storz - und der Ministerialrat im Innenministerium Spindler. Seit 1926 gehörte auch die neugegründete Sparerbundkasse zur Organisation, für deren Dienste etwa mit dem Slogan geworben wurde, man gebe die neu erübrigten Groschen nicht denjenigen, die einen seinerzeit betrogen hätten ${ }^{76}$. Insgesamt stellte Württemberg mit flächendeckenden

71 Ebd., S. $93 \mathrm{f}$.

72 Ebd., S. 94 f. Diese einseitige Haltung wurde jedoch schon 1929 relativiert: Die damals beschlossenen „Richtlinien“ betonten, dass man „sowohl das großkapitalistische als auch das sozialistische Wirtschaftssystem" bekämpfe. Zitiert nach FrITsCH (wie Anm. 65) S. 741.

73 Adolf Bauser, Notwendigkeit (wie Anm.66) S. 95.

${ }^{74}$ Ebd., S. 94 f.

75 Ebd., S. 91.

76 Selbsthilfe Nr.13 vom 17.7.1926 (Anzeige). Bauser war dort Vorsitzender des Aufsichtsrates, ab 1939 „leitendes Vorstandsmitglied“. Vgl. Hans Bauser (wie Anm.6) hier S. 10 . 
Vertretungen einen der führenden Verbände im Reich dar, ablesbar auch an der Stellung Bausers.

So war es naheliegend, dass der erste Reichsparteitag, verbunden mit einer Reichstagung der Sparer, im Oktober 1927 in Stuttgart stattfand. Hier traten neben Bauser und Spindler eine Anzahl auswärtiger Redner auf; auch Behördenvertreter waren anwesend. Das Themenspektrum umfasste neben der Aufwertung die Hauszinssteuer, die Daweslasten, Rentnerversorgung, schließlich Angestelltenund Mieterfragen. Die große Kundgebung stand unter dem Motto: „Der Kampf um das Recht“, Hauptredner war der frühere Staatssekretär und jetzige Ehrenvorsitzende der VRP, Graf von Posadowsky-Wehner. Neben seiner Kritik der ungerechten Aufwertungsgesetze stellte er fest, die Regierung solle froh sein über das Erscheinen der VRP, denn sonst würden Zebntausende entrechteter Sparer die Kommunisten wählen. In einer Entschließung wurde einstimmig die Wiedergutmachung des Inflationsunrechts, eine wirkliche Neuregelung der Aufwertung, schließlich der Widerruf der Erklärung von Deutschlands angeblicher innerer Entschuldung gefordert. Damit wäre die Grundlage für die Revision des Dawesplanes geschaffen ${ }^{77}$.

\section{„Kampfbund“ der Millionen oder Splitterpartei? - Von den Doppelwahlen 1928 zur Reichstagswahl 1930}

Während die VRP große Hoffnungen auf die kommenden Wahlen setzte ${ }^{78}$, opponierten die etablierten Parteien gegen die neuen Splitterparteien und deren Ziele $^{79}$. In zwei Vertreter-Versammlungen beriet die VRP über die Wahlen und die zu nominierenden Kandidaten. Dabei war man sich bewusst, dass das bestehende Wahlrecht die Partei sowohl im Reich als auch im Land benachteilige. Dagegen wurde protestiert und auch der Landtag eingeschaltet, allerdings ohne Erfolg ${ }^{80}$. Nominiert wurden als Spitzenkandidaten für den Landtag Bauser und Rechtsanwalt Hagel (Landesliste), für den Reichstag Bauser und Spindler ${ }^{81}$.

Es lag auf der Hand, dass die VRP sich im Wahlkampf weitgehend auf die Aufwertungsfrage, deren Vorgeschichte einer gewollten Inflationspolitik und die

77 StAnz Nr.250 vom 26.10.1927, KB Nr.249 vom 25.10.1927.

78 Unmittelbar davor hatte die württembergische Regierung ihre zahlreichen, jedoch gescheiterten Schritte zur Verbesserung der Aufwertungsgesetzgebung publiziert. Ihrer aufwertungsfreundlichen Haltung war es jedoch gelungen, dass hier die Sparkassenanleihen höher als anderswo aufgewertet wurden. Mainhardter Wald-Bote, Nr.76 vom 19.5.1928.

${ }^{79}$ So erklärte etwa die DVP, das Programm der VRP bedeute Zusammenbruch der Wirtschaft und der Staatsfinanzen und damit neue Inflation. Wahlnachrichten Nr.3 vom 18.5.1928. Vgl. auch deren Nummern 1 und 2.

${ }^{80}$ StAnz Nr. 11 vom 14.1.1928, KB Nr.65 vom 17.3.1928.

81 KB Nr. 95 vom 24.4.1928. 
Sünden des derzeitigen Systems konzentrierte: Dies bedeutete scharfe Kritik an der Parteiwillkür und den bisherigen Regierungen sowie an Verfassungsverletzungen wie das abgelehnte Volksbegehren oder Wahlrechtsbeschränkungen. Die Verantwortlichen sollten - besonders für die lügnerische Erklärung der inneren Entschuldung Deutschlands - vor dem Staatsgerichtshof zur Rechenschaft gezogen werden. Neben diese illusionäre Hoffnung traten Ausfälle gegen die Parteien und Regierung korrumpierende Hochfinanz. Demzufolge lehne allein die VRP Aufsichtsratsposten für ihre Repräsentanten ab. Sie erstrebe eine Mittelstandspolitik, bei der das Volksvermögen möglichst breit gestreut sei. Ihr ganzer Einsatz gelte den geschädigten Volksgenossen und dem Kampf gegen die durch Inflation und Aufwertungsgesetze hervorgebrachte skrupellose Gewinnsucht. Immerhin konnte man auf in Sachsen bereits erreichte Verbesserungen bei der Sparkassenaufwertung verweisen $^{82}$.

Ein an Bauern, Handwerker, Handel- und Gewerbetreibende gerichtetes Flugblatt präsentierte ein Schuldregister der Nachkriegspolitik, die letztlich darin bestanden habe, alle Lasten auf die deutschen Sparer - auch auf Euch - abzuwälzen. Mitverantwortlich für die gegenwärtige Volksnot seien die alten Parteien, denen sich nun die VRP entgegenstelle, um aus einem Raubstaat wieder einen Rechtsstaat zu machen. Sie erstrebe nicht nur die Wiederherstellung des enteigneten Volksvermögens, sondern die Herabdrückung der gegenwärtigen Zinsen, eine Stärkung der Kaufkraft, die Sicherung der Währung und kämpfe gegen großkapitalistische Ausbeutung und die erdrückenden Daweslasten ${ }^{83}$.

Auch in der Provinz war die Partei mit Wahlversammlungen präsent. So gestand Spindler in Gaildorf die Problematik der Partei-Zersplitterung in Deutschland ein, gab jedoch zu bedenken, dass angesichts des Versagens der Reichsregierung und der meisten Parteien die Gründung der VRP ein zwangsläufiger Akt der Selbsthilfe gewesen sei. Ein Parteifreund verwies dort auf die 70.000 Notselbstmörder in Deutschland als Folge der Aufwertungsgesetze und betonte, wie das Versprechen der als absolut sicher bezeichneten Kriegsanleihen gebrochen wurde, während inzwischen sowohl die Sparkassen, die größeren Städte als auch die Industrie sich in guter Lage befänden ${ }^{84}$.

Fraglos waren die Wahlergebnisse für die Partei trotz ihres großen Einsatzes ernüchternd. Sie erzielte bei den Landtagswahlen etwa 37.000 Stimmen und konnte ihr Ergebnis von 1924 nicht wesentlich verbessern; sie blieb - vorläufig ohne Mandate. Auch für den Reichstag konnten nur zwei Sitze (Best und Lobe)

82 Auszug aus dem Wahlaufruf, KB Nr.114 vom 16.5.1928. Der komplette Aufruf im Reichstags-Handbuch für die 4. Wahlperiode, Berlin 1928, S. 194-198.

83 Im Original z. T. in Fettdruck. Das Flugblatt ist dem KB beigeheftet. Vgl. auch die Anzeigen im KB Nr. 112 vom 14.5.1928 und Nr. 115 vom 18.5.1928.

${ }^{84} \mathrm{~KB}$ Nr.106f. vom 7.5.1928 und 8.5.1928. Vgl. auch KB Nr.116 vom 19.5.1928 (Versammlung in Michelbach/Bilz im Oberamt Gaildorf). 
gewonnen werden, obwohl mit insgesamt ca. 480.000 Wählern ein respektables Ergebnis - wenn auch nicht die von Bauser erwarteten Millionen - erreicht wurde $^{85}$. Gegen die schon im Vorfeld befürchtete Benachteiligung durch die Wahlgesetze setzte sich die Partei zur Wehr. Im Reich, wo rechnerisch 60.000 Stimmen für ein Mandat erforderlich waren, gingen so etwa 360.000 Stimmen verloren. Dies veranlasste die Reichspartei, beim Leipziger Staatsgerichtshof Einspruch zu erheben ${ }^{86}$, der jedoch erfolglos blieb. Auch für Württemberg reichte man dort Klage ein, hätten der Partei doch rechnerisch zwei bis drei Sitze zugestanden. Deren Verweigerung unter Berufung auf das Wahlrecht werde als schweres Unrecht und zugleich als Verletzung des Prinzips der Wählergleichheit empfunden ${ }^{87}$.

Zum Wahlergebnis ist anzumerken, dass offenbar Teile der erhofften Wähler zur Wirtschaftspartei gestoßen waren, die ein vergleichsweise umfassenderes Programm präsentierte. Zudem blieben die Inflationsgeschädigten organisatorisch weiterhin zersplittert und konkurrierten miteinander, schließlich gab es sogar innerhalb der VRP Querelen ${ }^{88}$. So war die zukünftige Entwicklung der Partei ungewiss.

Ungeachtet der Wahlerfahrungen blieb die Partei weiterhin auf ihr zentrales Thema fixiert, für das sie reichsweit durch Protestversammlungen warb. So wurden während einer gut besuchten Stuttgarter Kundgebung im Oktober 1928 Unterschriften für eine Entschließung gesammelt, die die Wiedergutmachung des Währungsbetrugs, die restlose Klärung des Kriegsanleibeskandals, den Widerruf der Regierungslüge von Deutschlands innerer Entschuldung und schließlich eine Reduzierung der Daweslasten forderte ${ }^{89}$. Einer Erweiterung ihres zentralen Politikfeldes wich die Partei aus. Ein Beispiel dafür war der Beschluss des Reichsvorstandes, zu der umstrittenen Frage um den Bau des Panzerkreuzers „A “90 keine Stellung zu beziehen; man wolle sich nicht in den Parteienstreit einmischen ${ }^{91}$. Bauser fand, dies sei eine „Bagatelle gegenüber dem großen Kampf um das Recht“92.

Im Vorfeld der Sachverständigen-Verhandlungen über die Neuregelung der Reparationen im Frühjahr 1929 verfasste Ministerialrat Spindler für seine Partei eine Denkschrift, die an die Reichsregierung, die Regierungen der Länder, die Parlamente sowie die deutschen Sachverständigen gesandt wurde. Eine englische

${ }^{85}$ Dies gilt insofern, als die reichsweite Mitgliedschaft auf etwa 50.000 geschätzt wurde. Vgl. Fritsch (wie Anm. 65) S. 739. In Württemberg lagen die Ergebnisse über dem Reichsdurchschnitt; eine Mitgliederzahl konnte nicht ermittelt werden.

${ }^{86}$ Vgl. KB Nr.126 vom 1.6.1928.

87 StAnz Nr. 119 vom 23.5.1928.

88 Vgl. dazu Fritsch (wie Anm. 65) S. 742.

89 KB Nr. 243 vom 16. 10.1928.

90 Vgl. dazu etwa Heinrich August Winkler, Weimar 1918-1933, München 1998, S. $332 \mathrm{f}$.

${ }^{91}$ KB Nr.238 vom 10.10.1928.

92 Zit. nach Fritsch (wie Anm. 65) S. 742. 
Übersetzung sollte im Ausland verbreitet werden ${ }^{93}$. Spindlers Argumentation, die wesentlich auf einer Veröffentlichung des Basler Nationalökonomen Ritschl basierte, ging davon aus, dass die überhöhten Daweslasten auf der nacbweislich falsche[n] Annabme beruhten, die Inflation habe die Schulden des Reiches, der Industrie und der Hausbesitzer ausgelöscht. In Wahrheit sei diese Schlussfolgerung einer inneren Entschuldung Deutschlands nach Ritschl jedoch ein Taschenspielertrick gewesen, aufgebaut auf einer Vermögensvernichtung und resultierend in verheerenden sozialen und wirtschaftlichen Konsequenzen. Dementsprechend forderte die Denkschrift die Herabsetzung der Reparationsleistungen um mindestens die Hälfte. Davon erwarte man sowohl die Wiedergesundung der Wirtschaft als auch die Wiederherstellung rechtlicher und sittlicher Normen.

Diese Initiative musste jedoch zwangsläufig ins Leere stoßen. Die von der VRP unbeirrt bekämpfte „Entschuldungslüge ${ }^{\text {“94 }}$ war zwar moralisch nachvollziehbar. Da sie jedoch das Fundament der Reparationsregelung darstellte, die wiederum mit der angestrebten Räumung des Rheinlandes verbunden war und zudem früheres Regierungshandeln diskreditierte, war die Hoffnung auf einen Erfolg naiv. Dennoch war Bauser sogar nach Paris gereist, um die Unterhändler auf diesen Sachverhalt aufmerksam zu machen ${ }^{95}$. Folgerichtig lehnte schließlich die VRP den Youngplan ab, der ihre Entschuldungsforderung unberücksichtigt ließ. Trotz ihrer Gegnerschaft beteiligte sie sich jedoch nicht an dem vom neuen DNVP-Vorsitzenden Hugenberg im Verein mit Hitler organisierten demagogischen Volksbegehren gegen den $\operatorname{Plan}^{96}$.

Im Juni 1929 durfte die württembergische VRP einen Erfolg ihrer Anfechtung der Sitzverteilung bei der vorjährigen Landtagswahl verbuchen. Nach einer Entscheidung des Reichsgerichts war vom württembergischen Staatsgerichthof ein Urteil ergangen, das - zu Lasten von SPD, Zentrum und Bauernbund - der Partei zwei Mandate zusprach, ein weiteres ging an die NSDAP ${ }^{97}$. Am 11. Juni traten so Bauser und Rechtsanwalt Eugen Hagel ${ }^{98}$ aus Stuttgart in das Landesparlament

93 Vgl. zur Denkschrift den Artikel von Bauser im KB Nr.41 vom 18.2.1929.

${ }_{94} \mathrm{Zu}$ diesem Dauerthema der Partei erhob namentlich Spindler schwere Vorwürfe gegen die Regierung. Während die Alliierten ihre inländischen Schulden beibehielten, hatten die ausländischen Sachverständigen 1923 auf die deutsche Erklärung getilgter inländischer Schulden durch den Währungsverfall ihre Forderungen verdoppelt. Ohne diese Erklärung, so damals Dawes, seien weitaus niedrigere Forderungen erhoben worden. Das damalige Handeln der Reichsregierung erheische, so Spindler, „strenge staatsgerichtliche Untersuchung“. Dazu Spindlers Aufsatz: Die öffentlichen Anleihen, in: Für Wahrheit und Recht (wie Anm.7) S.23-53, hier insbesondere S.27-30 (Zitat).

${ }_{95}$ Rede in Gaildorf, KB Nr.62 vom 15.3.1932.

96 KB Nr. 235 vom 7.10.1929.

97 KB Nr.134 vom 11.6.1929.

98 Vgl. zu Hagel (1884-1953) Raberg (wie Anm.6) S. 313. 
ein - ihr Wirken wird später behandelt. Die VRP konnte so eine stärkere öffentliche Wahrnehmung erwarten.

Diesem Ziel diente auch der Beschluss der gemeinsamen Landesversammlung von VRP und Sparerbund, die „Selbsthilfe“ ab 1.4.1930 wöchentlich herauszugeben. Kritik wurde an den Plänen der Reichsregierung geübt, ihre gläubigerschädigende Gesetzgebung fortzusetzen, während doch eine Reform der Aufwertungsgesetze zur Gesundung des Inlandskredits und zur Senkung der Realzinsen führe. Im Zeichen der Wirtschaftskrise wurden programmerweiternde Forderungen erhoben: so nach einer produktiven Erwerbslosenfürsorge, einer Urbarmachung der Oedländereien, der Förderung ländlicher Siedlungen sowie einer Staats- und Verwaltungsvereinfachung. Schließlich sollte im Interesse des Mittelstandes eine Wirtschaftspolitik stehen, die die Zusammenraffung des Volksvermögens durch die großkapitalistischen Erwerbsgesellschaften, aber auch die öffentliche Hand beseitige $^{99}$. Auch während des Reichsparteitags der VRP im März in Leipzig betonte der Ehrenvorsitzende von Posadowsky-Wehner die Bedeutung der derzeit bekämpften Sozialpolitik. Deren Ausbau im Zeichen der Krise sei sittliche Pflicht gegenüber einer bilflose[n] Minderbeit. Insofern seien sowohl Steuersenkungen als auch unverantwortliche Parteiforderungen fehl am Platz; die Partei werde das allgemeine Staatswohl und die Bedürfnisse aller Bürger vertreten. Bausers Rede zur Außenpolitik erkannte im Völkerbund kein taugliches Instrument zur Regelung strittiger Fragen, forderte Gleichheit bei der Abrüstung und reklamierte Deutschlands Recht auf Kolonien. Zudem bemängelte er, dass weder die Kriegsschuldlüge noch die von Deutschlands innerer Entschuldung bei den Verhandlungen zum Youngplan bekämpft worden seien ${ }^{100}$,

Im Zeichen der mit der Wirtschaftskrise verbundenen Parteienkrise suchte die VRP nach Allianzpartnern. Sie hatte bei den sächsischen Landtagswahlen im Juni 1930 einen erheblichen Stimmenrückgang zu verzeichnen und eines von zuvor drei Mandaten verloren ${ }^{101}$. Während ihres Parteitags im Juli 1930 gab Bauser ein Wahlbündnis mit der Christlich-Sozialen Reichspartei bekannt ${ }^{102}$, das auch von den Württembergern begrüßt wurde. Dort forderten die Delegierten einer Landesversammlung für den kommenden Reichstagswahlkampf eine radikalere Haltung ${ }^{103}$. Der neue Partner war ungewöhnlich, da er eine linkskatholische Splitterpartei darstellte, die eindeutig links von der VRP stand ${ }^{104}$. Während die beiden Parteivorsitzenden Bauser und Heller an der Spitze des württembergischen, mit Baden

99 KB Nr. 32 vom 8.2.1930.

100 KB Nr. 65 vom 19.3.1930.

101 KB Nr. 143 vom 23.6.1930.

102 KB Nr.166 vom 19.7.1930.

103 KB Nr.171 vom 25.7.1930.

104 Vgl. Werner Fritsch, Art. Christlich-Soziale Reichspartei (CSRP) 1920-1933, in: Parteienlexikon, Bd.1, Leipzig 1983, S. 455-463. 
verbundenen Kreiswahlvorschlags standen, wurden zusätzlich u.a. noch Ministerialrat Spindler und der Landtagsabgeordnete Hagel nominiert ${ }^{105}$.

In einer Anzeige versprachen die Partner den Kampf gegen unerträglichen Stenerdruck, Youngplan, Arbeitslosigkeit, Steuer-Verschleuderung, Inflationsraub, Aufsichtsratsunfug [und] Notselbstmorde ${ }^{106}$. Diese Themen wurden dann in Versammlungen angesprochen. Während einer solchen in Gaildorf beschwor der einzige Stuttgarter VRP-Gemeinderat Wagner das erbabene Parteiziel einer Wiederherstellung des Rechts der Inflationsopfer, beklagte die Reparationslasten und wetterte gegen Hochfinanz und die Willkürherrschaft der Parteien. In einer gerechten Aufwertung sah er ein Allheilmittel gegen die Krise. Die Rettung Deutschlands sei nicht mit Gewalt und Diktatur, sondern nur durch einen wabren Volksstaat zu erreichen ${ }^{107}$. Auf einer Stuttgarter Kundgebung stellte Hagel die Parteiziele unter das Motto Volksrecht bricht Volksnot, eine Rednerin appellierte an Frauen und Mütter, gegen das Unrecht anzugehen, Bauser betonte, der Kampf gegen den Youngplan müsse von der Entschuldungsfrage ausgehen ${ }^{108}$.

Der Wahlausgang vom 14. September bedeutete vor allem eine Katastrophe für die Demokratie, war doch die vormalige Splitterpartei NSDAP mit 107 Mandaten zur zweitstärksten Partei im Reichstag geworden. Die Hinwendung der Wähler zur Hitlerpartei war zweifellos mitverantwortlich für das deprimierende Ergebnis nicht nur der Allianz von VRP und CSRP. Während der VRP rechnerisch bei den auf sie entfallenden ca. 272.000 Stimmen fünf Sitze zugestanden hätten, bewirkte das ungünstige Wahlrecht, dass kein einziges Mandat gewonnen wurde. Auch die in Württemberg erzielten ca. 29.000 Stimmen markierten, analog zum Reichsergebnis, einen Verlust von etwa 12.000 Wählern und damit die Tatsache, dass das hehre Parteiziel im Zeichen der allgemeinen Krise weitgehend als unrealistisch wahrgenommen wurde. So stand die Partei vor einer nicht zu leugnenden Krise.

\section{Im Zeichen der Wirtschafts-, Staats- und Parteienkrise 1930-1932/1933}

Ungeachtet ihrer schwindenden Wählerresonanz hielt die VRP weiterhin unbeirrt an ihrem Kurs fest. Noch im Mai 1932 - nach dem Verlust ihrer württembergischen Landtagssitze - erklärte Bauser vor der Landesversammlung, an der sachlichen Richtigkeit und Notwendigkeit des Sparerkampfes und des Volksrechtskampfes habe sich nichts geändert ${ }^{109}$. Dies bewies zwar Prinzipientreue, aber es war keine Zukunftsoption. Allerdings war man verstärkt auf der Suche nach Allianzpartnern. Dies soll am Kapitelende betrachtet werden.

\footnotetext{
105 StAnz Nr. 199 vom 27.8.1930.

106 KB Nr. 201 vom 29.8.1930.

107 KB Nr. 203 vom 1.9.1930.

108 StAnz Nr. 208 vom 6. 9.1930.

109 KB Nr. 119 vom 25.5.1932.
} 
Dem Ziel einer verstärkten öffentlichen Präsenz diente Ende November 1930 ein deutscher Aufwertungs- und Wirtschaftskongress in Stuttgart, ausgerichtet vom Reichs-Sparerbund. Vor Behördenvertretern, Gästen und Rednern auch aus dem Reich plädierte hier Bauser für eine Wiedergutmachung der ungerechten Aufwertungsgesetzgebung als Weg, der aus der Krise führe. Reform oder Gewalt lautete für ihn die Alternative. Sein Kollege Hagel betonte, dass man keineswegs eine $100 \%$ ige Kompensation erwarte, aber moralische, wirtschaftliche und rechtliche Gründe sprächen für eine Aufwertungsreform. Diese sei letztlich der Schlüssel zur Lösung auch anderer Probleme wie etwa die Kapitalflucht. Eine Resolution sprach sich als ersten Schritt zur Umkehr für die Einberufung eines Sachverständigen-Ausschusses durch die Reichsregierung aus, der die Reform der Aufwertung in Verbindung mit anderen brennenden Problemen prüfen sollte.

Der anschließende Reichsparteitag forderte in einer Entschließung zur Außenpolitik etwa den Anschluss Österreichs an Deutschland, die Rückgabe der Kolonien, die Befreiung von der Vorberrschaft des internationalen Finanzkapitals sowie die Revision des Youngplans und des Versailler Vertrags. Innenpolitisch wurden insbesondere mittelständische Ziele und solche im Interesse der Landwirtschaft, des Handels und der Gewerbe, aber auch der Beamten artikuliert, verbunden mit der Forderung auf Schonung der wirtschaftlich Schwachen. So erhoffe man eine neue Volksgemeinschaft unter Einschluss der Jugend. Während ein auswärtiger Redner vor einem Zusammengehen mit den Nationalsozialisten warnte, wurde wiederum gefordert, die Schuldigen an der Inflation gerichtlich zu belangen ${ }^{110}$.

Auch weiterhin blieb die Partei bemüht, zusätzliche Politikfelder zu besetzen. So referierte im Januar 1931 ein englischer Generalstabsoffizier, bekannt als entschlossener Kämpfer gegen die Kriegsschuldlüge, in Stuttgart vor VRP-Mitgliedern und solchen des rechtsgerichteten Stahlhelms. Seine Kernaussage lautete, die Lüge von der Alleinschuld Deutschlands am Weltkrieg müsse zurückgewiesen werden. Bauser unterstrich dort die Verbindung zwischen Reparationsbelastung, Kriegsschuldlüge und Entschuldungslüge ${ }^{111}$ und kam immer wieder auf diesen Punkt zurück $^{112}$.

In einem Vortrag in Gaildorf forderte er, diese Thematik müsse Volksangelegenbeit, der Volkskampf gegen den Youngplan zur deutschen Lebensgrundlage werden. Bezüglich der die Gaildorfer besonders berührenden Frage der Reduzierung der Oberämter, argumentierte er opportunistisch im Sinne der Zuhörer, indem er die Gefabr einer starken Bürokratisierung und Schädigungen für Stadt und Bezirk beschwor. Er werde daher im Landtag entsprechend wirken ${ }^{113}$.

110 KB Nr. 282 vom 2.12.1930, StAnz Nr. 281 vom 1.12.1930.

111 KB Nr.12 vom 16.1.1931.

112 Vgl. KB Nr. 62 vom 15.3.1932.

113 KB Nr.62 vom 16.3.1931. 
Die nachfolgenden Landesversammlungen der VRP reflektierten die fortschreitende Krise in Staat und Wirtschaft. Im September wurden in einer Entschließung etwa die Finanznot der öffentlichen Hand, die Kapitalkrise der Wirtschaft und die steigende Arbeitslosigkeit thematisiert. Zur Problemlösung offerierte Bauser wiederum alte Rezepte wie die Wiederherstellung des alten Volksvermögens, verbunden mit der Sicherung der Spareinlagen und Bekämpfung von Inflationsplänen. Gegen die großen Kapitalverschieber, die preistreibenden Kartelle und Syndikate sowie die Börsenspekulation wurde energisches Vorgehen gefordert. Sparmöglichkeiten sah er auf den Gebieten der Gesetzgebung, Verwaltung und Justiz ${ }^{114}$.

Die sehr gut besuchte Landesversammlung im Januar 1932 stand bereits im Zeichen der Landtagswahl im April. Bauser referierte über ein Kampfprogramm, für das er den Rechtsgedanken - die Sparerforderungen - zum Leitmotiv erklärte. Dafür zu kämpfen erschien ihm nötiger als je zuvor. Man erstrebe ansonsten die völlige Beseitigung der Reparationslasten und protestiere mit größter Schärfe gegen die Notverordnungspolitik. Schließlich sollte der Wahlkampf möglichst ohne Bündnisse mit größter Energie geführt werden ${ }^{115}$.

Als wählerwirksam empfand die VRP mit Sicherheit eine Audienz bei Hindenburg im April für eine mehrköpfige, von Bauser geführte Parteidelegation. Nach den dort vorgebrachten Sorgen wegen inflationistischer Bestrebungen, den Notverordnungen, der Osthilfe und Passivität der Reichsregierung bezüglich der Sparerwünsche hatten die Bittsteller einen durchaus positiven Eindruck und hofften, dass sich der Präsident für ihre Anliegen einsetzen werde. Die Anhänger der Partei wurden aufgefordert, im zweiten Durchgang der Präsidentenwahl für Hindenburg zu stimmen ${ }^{116}$.

Der unermüdliche Bauser hatte im März in Gaildorf für seine Partei geworben. Auch dort äußerte er Sorgen vor einer von Schwerindustrie und Großgrundbesitz zu ihrer Entschuldung gewünschten neuen Inflation, in deren Kontext er auch das Osthilfegesetz sah. Enteignungspolitik zeige sich auch in den Notverordnungen; es gelte so eine starke Abwebrfront zu bilden. Zur Zuspitzung der Arbeitslosigkeit äußerte er den Befund, sie sei durch Tributleistungen, vor allem aber die zu bekämpfenden Inflationsschäden verursacht. Er forderte schließlich eine umfassende Siedlungspolitik und die Einführung einer Arbeitsdienstpflicht und propagierte den Volksrechtskampf gegen die Entschuldungslüge zugleich als Schlüssel zur Repara-

114 StAnz Nr.221 vom 22.9.1931.

115 KB Nr. 9 vom 13.1.1932.

116 KB Nr. 82 vom 9.4.1932. - In diesem Zusammenhang sei erwähnt, dass sich Bauser seit 1931 mehrfach um - wählerwirksame - Gesprächstermine in Berlin bemüht hatte. Vgl. HStA Stuttgart E 130 b Bü 2197. - Die Hindenburg vorgetragene Sorge um die Osthilfe entbehrte nicht der Pikanterie: Bei dieser einseitig den Großgrundbesitz begünstigenden Hilfe war der Präsident als Besitzer des ostpreußischen Gutes Neudeck sozusagen Partei. 
tionsfrage. Dieser Kampf basiere auf dem Rechtsempfinden der Partei und nicht wie bei der NSDAP auf Gelüsten nach Macht und Diktatur ${ }^{117}$.

Im Wahlaufruf der Partei wurde der Volksrechtskampf als dritte[r] Weg abseits von der plutokratischen Parteienwirtschaft und einer Diktatur erneut beschworen. Er sei Mittel zur Erhaltung der staatlichen und gesellschaftlichen Fundamente, die auf Recht und Gerechtigkeit basierten ${ }^{118}$. In einem Aufruf Bausers wurden die genannten Argumente als Weg der Rettung erneut artikuliert; als Motto gelte: Das Stener herum! Dafür setzte er große Hoffnungen auf Hindenburg ${ }^{119}$. In einer Anzeige warb die Partei für ihren kampferprobten Fübrer Bauser und bezeichnete das Wollen der Partei als Tatchristentum ${ }^{120}$.

Der engagierte Wahlkampf der VRP ${ }^{121}$ wurde von den verunsicherten und zum großen Teil auch radikalisierten Wählern nicht honoriert. Der Weg in den Abgrund war durch den Erdrutschsieg der inzwischen landesweit omnipräsenten NSDAP vorgezeichnet, konnte sie doch 23 Mandate erreichen, zuvor hatte sie einen Sitz. Während etwa die Demokraten die Hälfte ihrer Sitze verloren, verschwanden die DVP und die VRP aus dem Landesparlament. Letztere konnte nur noch ca. 16.300 Wähler mobilisieren; ihr Stimmenanteil war auf 1,3 \% gesunken ${ }^{122}$.

Unmittelbar nach der Wahl rief der deutschnationale Abgeordnete Wider zur bürgerlichen Sammlung auf, für die er seine Partei als Kern empfahl. Sein Appell war an DVP und VRP gerichtet, die er nationalpolitisch im eigenen Lager sah ${ }^{123}$. Seine Initiative blieb jedoch ohne Resonanz.

Während die VRP auf ihre zentralen Forderungen letztlich nicht verzichten konnte, versuchte sie verstärkt, durch Wahlallianzen einen Rettungsanker zu finden. Bauser hatte bereits 1931 das „Schicksal der Mittelparteien“ skeptisch beurteilt ${ }^{124}$ und nach der Landtagswahl 1932 zur „Sammlung des Bürgertums“ aufgerufen $^{125}$. Dazu führte er Verhandlungen sowohl auf Landesebene als auch in Berlin.

117 KB Nr.62 vom 15.3.1932.

118 KB Nr.91 vom 20.4.1932.

119 KB Nr. 92 vom 21.4. 1932.

120 KB Nr.93 vom 22.4.1932.

121 Dazu gehörte auch ein erneutes Plädoyer Bausers für die Erhaltung Gaildorfs als Oberamtssitz. KB Nr.93 vom 22.4.1932.

122 Im Verein mit der DVP und den Volkskonservativen entschloss sich die VRP erneut zu einer - erfolglosen - Wahlanfechtung. Man argumentierte, die getrennte Berechnung der Landes- und der Bezirkssitze habe die Kleinparteien benachteiligt, rechnerisch hätte ihnen je ein Mandat zugestanden. KB Nr.109 vom 12.5.1932.

123 Fränkischer Grenzbote (Crailsheim) Nr. 98 vom 28.4.1932.

124 So ein Zeitungsartikel. Vgl. Larry Eugene Jones, Sammlung oder Zersplitterung? Die Bestrebungen zur Bildung einer neuen Mittelpartei in der Endphase der Weimarer Republik 1930-1933, in: Vierteljahrshefte für Zeitgeschichte, Jg. 25, Heft 3 (1977) S. 265-304, hier S.294, Anm. 137.

125 Ebd. 
Seit Frühjahr 1931 wurden geheime Gespräche mit den Volkskonservativen und der Wirtschaftspartei geführt, die eine Zusammenarbeit bei Kommunal-, Landtags- und Reichstagswahlen anstrebten. Überlegungen gingen auch dahin, Kontakte zum Christlichen Volksdienst und der DVP herzustellen. Vorerst führten diese jedoch nur zu einer Einheitsfront bei den Stuttgarter Kommunalwahlen. Im März 1932, also vor den Landtagswahlen, war ein Wahlbündnis zwischen der DVP und den Volkskonservativen (Nationale Volksgemeinschaft) und schließlich auch der Wirtschaftspartei abgeschlossen worden. Darauf beschwerte sich Bauser, dass die VRP nicht informiert worden sei und fühlte sich düpiert. Im Vertrauen auf die einjährigen Verhandlungen habe man andere Möglichkeiten nicht genutzt ${ }^{126}$. Nach der Wahl meinte er, gemeinsam hätte man wobl sicher ein Mandat bekommen. Deren Ausgang kommentierte er drastisch: Jetzt würden zablreiche Nieten in den Landtag einziehen und dort ibr Unwesen treiben ${ }^{127}$. Ungeachtet dieser Erfahrung setzte er seine Bemühungen fort, gehörte er doch „zu den unermüdlichsten Verfechtern der bürgerlichen Sammlung “128. Darauf wird noch eingegangen.

Zuvor soll jedoch das Wirken der beiden VRP-Abgeordneten im Landtag zwischen 1929 und dem Schicksalsjahr 1932 kurz skizziert werden. Dabei ist ihnen eine durchaus konstruktive und letztlich regierungsfreundliche Haltung zu bescheinigen. Diese resultierte im Vorfeld der Landtagswahl 1932 in Spekulationen über eine Regierungsbeteiligung der Partei ${ }^{129}$, die im Verein mit dem Volksdienst mehrfach als "Zünglein an der Waage“ agiert ${ }^{130}$ und etwa gegen den Sturz Bazilles votiert hatte ${ }^{131}$.

Es lag auf der Hand, dass sich die Reden, die großen und kleinen Anfragen, Initiativen und auch die Ausschussarbeit der beiden Abgeordneten - Bauser gehörte dem Finanz-, Hagel dem Rechtsausschuss und dem Sonderausschuss für das Wahlgesetz an - schwerpunktmäßig auf die Aufwertungsfrage und deren immer wieder artikulierten negativen Folgen konzentrierten.

Daraus resultierten Appelle an die Landesregierung, in Berlin in ihrem Sinn zu wirken. Häufig wurde auch heftige Kritik an den Banken und ihren durch Krieg, Inflation und Aufwertung erzielten Gewinnen artikuliert. Hagel geißelte etwa die Kartellherrschaft und die steigende Zahl der Millionäre bei gleichzeitiger Zunahme

126 Bauser an Beißwänger und Hiller von Gärtringen von der Volksgemeinschaft, 29.3. 1932, Nachlass Hiller, Familienarchiv der Freiherren Hiller von Gärtringen, Gärtringen.

127 Bauser an Hiller von Gärtringen, 25.4.1932, ebd.

128 Jones (wie Anm. 124) S. 294. - Bauser war 1931 wohl wegen seiner vielen Aktivitäten nach Stuttgart verzogen, wo er als Oberschulrat wirkte.

129 Vgl. KB Nr. 91 vom 20.4.1932.

130 Vgl. etwa Waldemar Besson, Württemberg und die deutsche Staatskrise 1928-1933, Stuttgart 1959, S.60, 62.

${ }_{131}$ Vgl. Bauser an Beißwänger und Hiller von Gärtringen, 29.3.1932, Nachlass Hiller (wie Anm.126). 
der Selbstmörder ${ }^{132}$. Bei der Beratung des Sparkassengesetzes forderte er in einer - angenommenen - Entschließung eine verbesserte Aufwertung nach dem Muster von Sachsen oder Preußen ${ }^{133}$. Gepaart waren diese Initiativen häufig mit sozialpolitischen Forderungen im Interesse der Rentner und Kleinrentner oder der Arbeitslosen. Den Vorwurf, seine Partei tendiere zur Aushöhlung des Staates, wies Bauser empört zurück; ihre Forderungen kämen von Herzen ${ }^{134}$.

Das große Engagement für ihre eigentliche Klientel bedeutete jedoch nicht, dass man andere Themen ignorierte. War man im ureigenen Interesse um die Änderung des Wahlrechts bemüht, so wurde etwa für eine Vereinfachung der Verwaltung plädiert; allerdings war man, wie erwähnt, opportunistisch gegen eine Reduzierung der Oberämter. Kritisiert wurden ferner die Flut neuer Gesetze, die Osthilfe, die Kapitalflucht und natürlich der Youngplan. Mehrfach äußerte sich Bauser zu den Lehrerseminaren und setzte sich für die Belange der Volksschüler ein. Er betonte, am Nagolder Seminar sei nie Parteipolitik betrieben worden. Wichtig war ihm auch die Feststellung, seine Ernennung zum Schulrat in Stuttgart habe keine Beförderung bedeutet ${ }^{135}$. Vom Eifer der beiden Abgeordneten zeugt eine Statistik, nach der sie insgesamt 21 kleine Anfragen an die Regierung richteten. Dies waren mehr als bei den Demokraten und der DVP, die sowohl über mehr Abgeordneten verfügten als auch schon seit 1928 im Parlament wirkten ${ }^{136}$. Dass dieses Engagement dann von den Wählern nicht honoriert wurde, ist bereits betont worden.

Während die Partei weiterhin Hoffnungen auf die Etablierung des bei Hindenburg angeregten Sachverständigenausschusses und damit auf Prüfung ihrer Vorschläge setzte ${ }^{137}$, warf anschließend die kommende Reichstagswahl ihre Schatten voraus. Bauser wurde als Spitzenkandidat nominiert und bevollmächtigt, das günstigste Wablabkommen abzuschließen ${ }^{138}$. Schon im Juni suchte er in Berlin Kontakte mit verschiedenen Politikern, die jedoch ohne Ergebnis blieben, ebenso scheiterten auch Gespräche mit der NSDAP, für die im Zeichen der Krise nicht nur

132 StAnz Nr. 119 vom 26.5.1931.

133 KB Nr. 65 vom 18.3.1932. Auch Bausers Anträge in Sachen der ländlichen Siedlung, des freiwilligen Arbeitsdienstes und zur Preissenkung fanden Zustimmung. Ebd.

134 StAnz Nr. 162 vom 13.7.1929.

135 StAnz Nr.112 vom 16.5.1931.

136 Vgl. Fränkischer Grenzbote Nr. 92 vom 21.4.1932.

137 KB Nr.119 vom 25.5.1932 (Landesversammlung). - Die Einsetzung eines Ausschusses von Sachverständigen hatte Bauser schon im Sommer 1931 in einem vierseitigen Flugblatt „Volksnot und Volksrecht“ gefordert, das den 16.7.1925, d.h. die Annahme der Aufwertungsgesetze, als schwarze[n] Tag in der Geschichte des Deutschen Reichstags bezeichnete und die Inflation als Machenschaft eines kleinen Kreises von Politikern und Wirtschaftlern brandmarkte. Das Flugblatt im HStA Stuttgart E 130 b Bü 2197.

138 KB Nr. 155 vom 6.7.1932 (weitere Landesversammlung). 
bei der VRP zunehmende Sympathien laut wurden ${ }^{139}$. Als einziges Ergebnis seiner hektischen Betriebsamkeit konnte Bauser schließlich ein Abkommen mit dem Christlichen Volksdienst präsentieren, auf das man große Hoffnungen setzte ${ }^{140}$.

Sowohl in ihrem Wahlaufruf als auch in Versammlungen appellierte die VRP an Vernunft und Besinnung gegen den grassierenden verderblichen Massenwahn. Dem Fieber der Gewalt, dem Klassen- und Parteienkampf wolle man das Recht und die Idee der schicksalsverbunden Volksgemeinschaft entgegensetzen. Es gelte, den Irrwabn einer neuen Inflation als Hilfe für die Wirtschaft und damit eine erneute Sparerenteignung zu bekämpfen. Anzustreben sei eine auf Vertrauen basierende Inlandskapitalbildung, die Bekämpfung der Arbeitslosigkeit und die Heranziehung der arbeitslosen Jugendlichen zu einem Arbeitsdienst. Schließlich müsse die Forcierung des Siedlungsgedankens auch gegen den Widerstand der Großgrundbesitzer erfolgen. Als Kampfparole wurde formuliert: Arbeit und Eigentum, Freiheit und Recht im Innern und nach außen! $!^{141}$

Dass die Appelle und Rezepte der VRP dann keinen Einfluss auf den Massenwahn nehmen konnten, zeigte das Ergebnis der Juli-Wahlen: Mit knapp 41.000 Stimmen im Reich $(0,1 \%)$ und etwa $8.400(0,6 \%)$ in Württemberg war ihr deprimierender Tiefpunkt erreicht. Ungeachtet dessen verhalf das Abkommen mit dem Volksdienst Bauser zu einem Mandat ${ }^{142}$, das jedoch nur eine Episode darstellte; der Reichstag wurde bereits am 12. September aufgelöst. Die Zerstörung der Republik war in ihr finales Stadium getreten.

Am 18.9.1932 formierte sich in Berlin der Deutsche Nationalverein, der jedoch nicht, wie von Bauser erhofft, als Partei, sondern nur als vermittelnde „Gesinnungsgemeinschaft" wirken wollte ${ }^{143}$. Bauser bemühte sich im September und Oktober unermüdlich, sein Ziel einer Sammlung des bürgerlichen Lagers außerhalb der Deutschnationalen zu erreichen ${ }^{144}$. Hoffnungsvoll sprach er Ende September vor einer VRP-Versammlung in Stuttgart über den Ausweg aus der politischen Sackgasse durch die Sammlungspolitik. Die Bildung einer nemen nationalen Front sei das Gebot der Stunde. Die erhoffte Front habe einen Zweifrontenkrieg zu

139 Vgl. dazu Jones (wie Anm. 124) S. 294, Anm. 137. - Bauser an Hiller von Gärtringen, 5.6.1932 und 9.6.1932 (wie Anm.126). Im zweiten Schreiben war dann nebulös von einer neue [n] Partei in Berlin die Rede. Vgl. zu den NS-Kontakten FrITsch (wie Anm. 65) S.743 und StAnz Nr.174 vom 28.7.1932.

140 StAnz Nr. 174 vom 28.7.1932; vgl. auch Günter OpITz, Der christlich-soziale Volksdienst. Versuch einer protestantischen Partei in der Weimarer Republik, Düsseldorf 1969, S. 277.

141 Wahlaufruf im KB Nr. 173 vom 27.7.1932. Vgl. auch eine Stuttgarter Wahlrede Bausers mit ähnlichen Aussagen, StAnz Nr. 174 vom 28.7.1932.

142 Vgl. dazu KB Nr.178 vom 2.8.1932.

143 Jones (wie Anm.124) S.292f. Vgl. zum Deutschen Nationalverein (1932-1933) den Art. von Jürgen John/Kurt Rüss, in: Parteienlexikon, Bd.2, Leipzig 1984, S. 216-220.

${ }^{144} \mathrm{Vgl}$. zu seinen Gesprächen mit Vertretern von DVP, Wirtschaftspartei, Volksdienst und Demokraten: Jones (wie Anm.124) S.294 mit Anm.137, S. 296 mit Anm.151. 
führen, gegen den Sozialismus einer-, den Großkapitalismus andererseits, um so den Schutz des Eigentums einschließlich des Sparerkapitals zu gewährleisten ${ }^{145}$.

Etwa gleichzeitig wurde bekannt, dass sich die DVP zur DNVP orientierte ${ }^{146}$ und so die Einigungsversuche vor dem Scheitern standen. Am 4. Oktober fand eine außerordentliche Landesversammlung der VRP statt, bei der sich Bauser jedoch nicht zu den Parteigesprächen äußerte. Wiederum betonte er die Bedeutung Hindenburgs und die Notwendigkeit der zentralen Parteiziele. Beschlossen wurde die Teilnahme am kommenden Reichstagswahlkampf, für den Bauser wieder als Spitzenkandidat nominiert und zum Abschluss von Wahlabkommen ermächtigt wurde $^{147}$. Dazu unternahm er gleichzeitig einen letzten Versuch, um wenigstens in Württemberg ein Zusammengehen von VRP, Wirtschaftspartei, Volkskonservativen und dem Jungdeutschen Orden zu erreichen ${ }^{148}$.

Aber auch dieser Vorstoß blieb ohne Erfolg. Als kläglicher Ertrag aller Bemühungen kam schließlich eine erneute Listenverbindung mit dem Volksdienst zustande $^{149}$. Im Wahlkampf bekräftigte Bauser die schon so häufig artikulierten Argumente und Appelle an die Vernunft und sprach von Deutschlands Schicksalswende ${ }^{150}$.

Die Wählerverluste der NSDAP am 6. November konnten für die VRP kein Trost sein. Sie erlebte ein weiteres Desaster; der 1930 einsetzende Abwärts-Trend hielt an. So verlor sie in Württemberg etwa eintausend Stimmen im Vergleich zum Juli, während reichsweit ein kleiner Zugewinn erreicht wurde. In einer keineswegs resignierten Betrachtung konstatierte Bauser fehlende Geldmittel, ein kontraproduktives Verhalten des Volksdienstes in Sachsen und vor allem, dass zablreiche unserer Anbänger sich verleiten ließen, nationalsozialistisch zu wäblen. Sie hätten geglaubt, eine große Partei könne ihr Anliegen besser fördern, dabei aber übersehen, dass bei der NSDAP inzwischen eine sparerfeindliche Politik dominiere. Er kündigte eine Mobilmachung der Sparer-und Volksrecht-Bewegung an und rief zur Einheitsfront aller Vernünftigen auf ${ }^{151}$.

\footnotetext{
145 StAnz Nr. 229 vom 30.9.1932.

146 Fränkischer Grenzbote Nr.228 vom 29.9.1932.

147 Fränkischer Grenzbote Nr. 234 vom 6.10.1932.

148 Bauser an Hiller von Gärtringen, 4.10.1932 (wie Anm. 126).

149 Vgl. Opitz (wie Anm. 140) S.284, auch StAnz Nr. 253 vom 28.10.1932.

150 Wahlrede in Stuttgart, StAnz Nr.257 vom 2.11.1932.

151 Selbsthilfe Nr. 35 vom 12.11.1932. Das Blatt erschien inzwischen im Großformat und war VRP-Organ auch für Bayern und Hessen.
} 


\section{Von 1933 bis zum Tod Bausers}

Für das deutsche Schicksalsjahr 1933 und auch die Zeit danach bleiben einige Entwicklungen bzw. Hintergründe sowohl innerhalb der Sparerbewegung als auch beim Handeln der neuen württembergischen Regierung unklar. Mitte Januar berichtete der Stuttgarter NS-Kurier, die Ueberbleibsel von VRP, Wirtschaftspartei und ähnlicher Gebilde planten eine neue Partei, die Deutsche Volksgemeinschaft ${ }^{152}$. Tatsächlich hatte ein Arbeitsausschuss die Bildung einer newen politischen Front vereinbart, die in einer auch von Bauser unterzeichneten Einladung zu einem Vortrags- und Aussprache-Abend einlud ${ }^{153}$. Auch in einer weiteren Einladung wurde der Begriff Partei vermieden, vielmehr von einem Arbeitsfeld für die politisch Heimatlosen gesprochen ${ }^{154}$. Das wohl letzte Lebenszeichen dieser Gruppierung war ein Marbacher Tag am Ostermontag, an dem Bauser, den neuen Zeiten Referenz erweisend, die Vermählung des Geistes von Potsdam mit dem Geiste von Marbach beschwor. Er stellte die Neugründung vor und sprach schließlich mit ebenfalls anwesenden NS-Funktionären ${ }^{155}$.

Erstaunlicherweise markierte diese Anbiederung jedoch - noch nicht - das Ende der VRP nach Hitlers Machtantritt. Zunächst kündigte sie eine Klage gegen ihre erschwerte Teilnahme an der Reichstagswahl vom 5. März an ${ }^{156}$, dann wurde während einer außerordentlichen Landesversammlung beschlossen, auch nach der Wahl, zu der kein Bündnis erreicht werden konnte, weiterhin für die Sammlung aller staatsbejahenden Kräfte zu wirken ${ }^{157}$. Nachdem so eine Wahlbeteiligung der VRP unterblieb, beschloss der Reichsvorstand die Freigabe der Entscheidung ohne konkrete Empfehlung. Allerdings gelte es, den bisherigen Grundgedanken beizubehalten ${ }^{158}$.

War damit de facto der Abtritt der VRP von der politischen Bühne erfolgt ${ }^{159}$, blieb Bauser bemüht, die Existenz des Sparerbundes zu sichern. Im Juni 1933 wurde er mit einer Abordnung des Bundes sowohl von Ministerpräsident Mergenthaler als auch im Innenministerium empfangen und konnte dort dessen Wünsche vortragen. Mergenthalers Erklärung zur Aufwertungsfrage und zur Sicherheit der Währung waren befriedigend ${ }^{160}$, die Weiterarbeit schien so gesichert. Im

152 Nach dem KB Nr.12 vom 16.1.1933.

153 Einladung vom 23.1.1933, Nachlass Hiller (wie Anm. 126).

154 Einladung der Volksgemeinschaft vom 23.3.1933, ebd.

155 Hohenloher Bote (Öhringen) Nr. 90 vom 19.4.1933. Vgl. auch StAnz Nr.90 vom

19.4.1933 (Dort wurde das neue Gebilde als Deutsche Kulturgemeinschaft bezeichnet.)

156 StAnz Nr. 41 vom 18.2.1933.

157 StAnz Nr. 44 vom 22.2.1933.

158 KB Nr. 46 vom 24.2.1933.

159 Eine Quelle für die Parteiauflösung oder ihr Verbot in Württemberg war nicht zu ermitteln. Bauser plädierte im Frühjahr 1933 für ihr Fortbestehen und setzte sich damit in Gegensatz zur Führung des Sparerbundes. Vgl. Fritsch, Sparerbund (wie Anm. 2) S.142.

160 StAnz Nr. 141 vom 21.6.1933. 
September reichte der Sparerbund den Regierungsstellen Gesetzentwürfe von Dr. Best ein, die der Wiederherstellung der Sparvermögen galten, verbunden mit einer Denkschrift zur Änderung der Hauszinssteuer ${ }^{161}$.

Umso erstaunlicher war dann das nachfolgende Geschehen, dessen Hintergründe unklar blieben. Ende September war zu lesen, das Innenministerium habe für den Sparerbund einen Beauftragten bestellt und Bauser aus politischen Gründen seines Amtes enthoben. Gleichzeitig wurde eine Neuordnung angekündigt ${ }^{162}$. Während einer schon zuvor terminierten Versammlung, auf der auch Bauser sprechen wollte ${ }^{163}$, wurde dieser Sachverhalt in dessen Abwesenheit einer großen Audienz mitgeteilt ${ }^{164}$.

Bauser gab jedoch nicht auf. Im November 1933 kam es - vor unklarem Hintergrund - zu einem Zusammenschluss mit dem badischen Sparerbund zu einem gemeinsamen Landesverband, an dessen Spitze wiederum Bauser trat; die Satzung wurde auf das Führerprinzip umgestellt ${ }^{165}$. Bauser berichtete Mergenthaler, dieser Schritt sei nach längeren Verbandlungen mit der Partei erfolgt. Man fungiere nunmehr als nationalsozialistische Organisation und rein wirtschaftliche Sparervertretung im Dienst des neuen Staates. Dabei verwies er darauf, dass man schließlich seit Jahren das nationalsozialistische Prinzip Gemeinnutz vor Eigennutz vertreten habe ${ }^{166}$.

Dennoch blieb die Existenz des Sparerbundes weiterhin gefährdet. Das württembergische Innenministerium äußerte Bedenken gegen dessen parteipolitische Tendenz im Sinne der aufgelösten VRP und fortbestehende, die Bevölkerung beunruhigende Aufwertungsbestrebungen. Auch gegen Bauser habe man Einwendungen, da er früher der DDP angehört habe und mit einer Halbjüdin verheiratet sei. Allerdings gebe er an, bereits seit längerer Zeit mit der NSDAP kooperiert zu haben. Dennoch befürchte man, er verfolge Sonderinteressen politischer Art ${ }^{167}$.

Schließlich fiel im Sommer 1935 die Entscheidung. Das württembergische Innenministerium berichtete, der Sparerbund habe sich im Juli freiwillig aufgelöst und bezeichnete dies als einfachste Lösung ${ }^{168}$. Eine zusätzliche Komponente dieser Entwicklung waren tiefgreifende persönliche und sachliche Differenzen zwischen Bauser und dem Reichsverband, der schließlich im November 1938 aufgelöst

161 StAnz Nr.224 vom 26.9.1933.

162 StAnz Nr.227 vom 29.9.1933. Vgl. auch Wilhelm KohlhaAs, Chronik der Stadt Stuttgart 1918-1933, Stuttgart 1964, S. 65.

163 HStA Stuttgart E 130 b Bü 2197 (Einladung).

164 StAnz Nr. 230 vom 3.10.1933.

165 KohlhaAs (wie Anm. 162) S. 78.

166 Bauser an Mergenthaler, 23.12.1933, HStA Stuttgart E 130 b Bü 2197.

167 Württembergisches Innenministerium an Reichsministerium des Inneren, 28. 4. 1934, ebd.

168 Württembergischer Innenminister an Staatsministerium, 7.8.1935, ebd. 
wurde ${ }^{169}$. Demgegenüber blieben die Sparerschutzkassen und für ihre Zwecke auch die Presseorgane erhalten. Bauser fand so 1939 ein letztes Refugium an der Spitze der für die Kassen gebildeten Arbeitsgemeinschaft ${ }^{170}$. Dass Bauser schließlich 1946 erneut aktiv wurde - als Gründer und Vorsitzender des Bundes der Sparer und Fliegergeschädigten sowie als CDU-Landtagsabgeordneter ${ }^{171}$ - ist nicht mehr Teil dieser Untersuchung.

\section{Schlussbetrachtungen}

Adolf Bausers außerordentliches Engagement für die Inflationsgeschädigten entsprang zweifellos einem tief empfundenen Gerechtigkeitsgefühl, gepaart wohl mit einem starken Geltungsbedürfnis. Er und seine Mitstreiter empfanden das Handeln bürgerlicher Reichsregierungen sowohl bei der gewollten Inflation als auch der anschließenden Aufwertungsgesetzgebung als himmelschreiendes Unrecht und eklatanten Rechtsbruch zu Gunsten einer sich maßlos bereichernden Kapitalisten-Clique, resultierend in einer Enteignung des staatstragenden Mittelstandes. Zu diesem als Trauma empfundenen Geschehen trat noch die „Entschuldungslüge“, die aus ihrer Sicht für Deutschlands überhöhte Reparationsleistungen verantwortlich war und ebenfalls zum Sündenregister der Reichsregierung gehörte. Letztlich unterstellte man Berlin ein Komplott gegen die Gläubiger.

Aus dieser bitteren Erkenntnis bezog zunächst der Sparerbund im Reich wie in Württemberg die moralische Legitimation seines Wirkens, das zudem starke juristische Schützenhilfe erhielt. Hier setzte man zunächst auf die Unterstützung durch die Parteien. Während man dabei namentlich durch die DNVP ein Fiasko erlebte, wurde die konstruktive Rolle der SPD kaum gewürdigt - Bauser und seine Klientel waren zutiefst bürgerlich orientiert. So erschien die Initiierung eines Volksbegehrens als realistische Alternative. Dessen Vereitelung mit äußerst fadenscheiniger Begründung durch die Reichsregierung addierte sich zu deren Schuldkonto und setzte endgültig einen Prozess der Staats-Entfremdung der Inflationsopfer in Gang.

Die folgerichtige Gründung der VRP ${ }^{172}$ sollte ermöglichen, nunmehr unmittelbar auf das politische Geschehen einzuwirken. Doch schon die Wahlen von 1928

169 Ebd. Vgl. zur Auflösung auch Hughes (wie Anm.4) S. 167.

170 Fritsch (wie Anm. 2) S. 143.

171 Raberg (wie Anm.6) S.38.

$172 \mathrm{Zu}$ Recht wurde das Erscheinen der Splitterparteien als „sichtbarer Ausdruck einer tiefgreifenden Legitimitätskrise“ des Weimarer Parlamentarismus und seines Parteiensystems interpretiert: Larry Eugene Jones, In the Shadow of Stabilization: German Liberalism and the Legitimacy Crisis of the Weimar Party System, 1924-1930, in: Die Nachwirkungen der Inflation auf die deutsche Geschichte 1924-1933 (Schriften des Historischen Kollegs, Kolloquien, Bd.6), hg. von Gerald D. Feldmann, München 1985, S. 21 -41 (Zitat S. 41). 
bescherten nur einen Teilerfolg und keineswegs die von Bauser erhofften „Millionen“. Während Reichsparerbund und VRP zwar die stärksten Bataillone der Bewegung der Inflationsopfer bildeten ${ }^{173}$, blieb diese zersplittert und wurde durch konkurrierende Gruppierungen von Anfang an geschwächt. Seit den Wahlen von 1930 wurde dann deutlich, dass sich große Teile der potentiellen VRP-Klientel zur dramatisch erstarkten NSDAP wandten. So war die Partei auf die Rolle einer Splitter-Gruppierung reduziert. Ihre bisherigen Teilerfolge in Ländern wie Württemberg hatten nicht überzeugen können, die weiterhin propagierte Verbesserung der Aufwertung als wirtschaftspolitisches Allheilmittel musste im Zeichen der Krise ebenso wie die Hoffnungen auf Hindenburg als Illusion erscheinen.

Bausers unermüdliche, jedoch erfolglose Suche nach politischen Allianzpartnern war letztlich ein Verzweiflungsakt. Zusätzliche Forderungen etwa für Rentner oder Arbeitslose waren ehrenwert, Ausfälle etwa gegen die „Kriegsschuldlüge“ oder seine Kolonialforderungen waren auch anderswo $\mathrm{zu}$ findende politische Allgemeinplätze. Keineswegs zutreffend ist die Charakterisierung der VRP als „extrem rechts angesiedelt“"174.

Diesem Urteil widerspricht ihr letztlich konstruktives Verhalten im württembergischen Landtag, die zornerfüllten aber klischeehaften Ausfälle gegen das Großkapital und natürlich ihre gesamte Programmatik.

Bausers Haltung seit 1933 war schillernd und ambivalent. Keineswegs unehrenhaft versuchte er, sich zwecks Erhaltung des württembergischen Sparerbundes mit den neuen Machthabern zu arrangieren. Peinlich war allerdings seine Aussage über die „Vermählung“ des Potsdamer Geistes mit dem von Marbach. Dass die Machthaber ihm dennoch misstrauten, belegt die wohl erzwungene Auflösung des Bundes. Ob und inwieweit er als Schulmann Schwierigkeiten hatte, bleibt unklar. Sein vorzeitiges Pensionsgesuch von $1939^{175}$ lässt darauf schließen, allerdings trat er noch im Sommer1934 als Redner bei einer Tagung des Stuttgarter Bezirksschulamtes auf ${ }^{176}$.

Ein ungünstiges Licht auf ihn wirft ein nach Kriegsbeginn 1939 erschienener Aufsatz, in dem er die „Kriegsfinanzierung lobte“, sein Vertrauen in Hitler bekun-

173 Von der Landesgeschichtsschreibung wurde diese Bewegung erstaunlicherweise praktisch ignoriert. Im Handbuch der baden-württembergischen Geschichte, Bd.4: Die Länder seit 1918, hg. von Hansmartin Schwarzmaier, Stuttgart 2003, wird die VRP nur am Rande und ohne nähere Erläuterung erwähnt.

Willi Boelcke geht nur auf die Auswirkung der Inflation ein. Vgl. Willi Boelcke, Sozialgeschichte Baden-Württemberg 1800-1998: Politik, Gesellschaft, Wirtschaft (Schriften zur politischen Landeskunde Baden-Württembergs, Bd.16), Stuttgart 1989, S. 366.

174 So Klaus-Jürgen MATZ, Reinhold Maier (1889-1971). Eine politische Biographie, Düsseldorf 1989, S. 65.

175 Vgl. dazu Hans Bauser (wie Anm. 6) S.11.

176 KB Nr.162 vom 16.7.1934. 
dete und die Sparer beruhigte ${ }^{177}$. War dies nicht ein ohne Not erfolgtes Zuviel an Anpassung?

Nach Bausers Tod zollte ihm der Sozialdemokrat Wilhelm Keil im Landtag ein ehrendes Gedenken. Er lobte seine Unerbittlichkeit in der Aufwertungsfrage und auch sein politisches und gesellschaftliches Engagement nach Kriegsende ${ }^{178}$. In der Tat spricht dieser lange und zähe Einsatz für sein außerberufliches Lebenswerk.

177 Vgl. dazu Fritsch (wie Anm. 2) S. 143.

178 Nach StAnz Nr. 48 vom 27.11.1948. 